\title{
Seismic Toughness and Failure Mechanisms of Reduced Web- Section Beams: Phase 1 Tests
}

MYOUNGSU SHIN ${ }^{1}$, SEUNG-PIL KIM ${ }^{1}$, ARNE HALTERMAN ${ }^{2}$, and MARK ASCHHEIM ${ }^{3 *}$

Avoiding fracture in the beam-column connections of steel moment frames is critical to their seismic performance. Both Reduced Web Section (RWS) and Reduced Beam Section (RBS) methods apply the capacity design principle to shift the location of yielding into the beam and away from the beam-column connection. In the RWS approach, large openings are introduced into the web of the beam, so that the arrangement and configuration of the openings determine the mode of inelastic mechanism that develops within the beam. In this paper, experimental and numerical results are discussed for five RWS specimens that were subjected to reversed cyclic displacements. Also, the concept and potential inelastic modes of RWS beams are introduced, and beam shear equations corresponding to the assumed plastic mechanisms are derived. Of the five specimens, one had only two openings close to the beam-column connections, while the others had multiple openings distributed over the beam span. Most of the specimens exhibited stable hysteretic behavior up to approximately $6 \%$ story drift.

Keywords - Reduced web-section beam; Beam-column connection; Steel moment frame; Seismic behavior 


\section{Introduction}

33 The unexpected fracture of welded beam-column connections of steel moment frames in the 34 Northridge and Hyogo-Ken Earthquakes in the mid-1990s has motivated the development of 35 methods to improve the performance of the system [1,2]. Some methods focus on increasing the toughness of the beam-column connections $[3,4]$, while other methods aim to limit the intensity of stress at the connections by shifting the location of plastic hinging away from the beamcolumn welds. Examples of the latter include the use of haunches [5, 6, 7] and the removal of portions of the beam flange near the connections (known as a "Reduced Beam Section") [8, 9]. These approaches enforce yielding to develop in flexure at critical (weaker) locations away from the beam-column connections.

In the present study, an innovative method of reducing the shear strength of a wideflange beam is explored aiming at inducing yielding within the beam span due to beam shear; as a result of this mechanism, the intensity of stress at the beam-column welds is limited. Because steel beams of ordinary dimensions have ample shear strengths compared with the shear demands, relatively large openings must be introduced in the web to generate yielding due to beam shear. This approach to providing ductility to moment frames is termed the "Reduced Web Section" method [10].

Openings have been introduced into beam webs to facilitate the routing of utilities such as plumbing and electrical conduit, oftentimes necessitating reinforcement to ensure the opening is not a source of weakness [11]. In the case of castellated beams, flexural stiffness and strength are improved by longitudinally cutting the beam in two, offsetting the two parts, and welding the web in between the openings so formed. Such beams provide for passing utilities through the openings. Important phenomena that bear on the design of castellated beams have been described $[12,13,14]$ and synthesized into design criteria $[15,16]$. Castellated beams made from IPE, UB, and other shapes sections are widely available [17].

The use of girders having rectangular web openings reinforced by diagonal members was suggested for providing inelastic response to seismic motions [18]. The emphasis herein is the use of unreinforced web openings to promote ductile mechanisms associated with beam shear. Ten beam-column frame specimens, each comprising a Reduced Web Section (RWS) beam, were tested under reversed cyclic lateral displacements. This paper introduces design concepts for RWS beams subjected to lateral loading, describes results from numerical studies, and discusses the seismic toughness and failure mechanisms of the first five specimens, tested in 
companion paper [19].

\section{Concept of Reduced Web-Section Beams}

A beam in a moment-resisting frame subjected to lateral loading (Figure 1a) develops shear forces and bending moments along the span as shown in Figures $1 \mathrm{~b}$ and 1c, respectively. The bending moment is the highest at the beam-column connection and zero near the midspan, placing large stress (and strain) demands on the connection welds or bolts. Unlike the moment, the shear force is constant over the span of the beam if subjected to lateral loads only, and it is nearly constant when the shear forces due to gravity loads are relatively small.

Figure 1d illustrates that the resultant tensile and compressive forces caused by the bending moment are developed primarily in the beam flanges. For the moment equilibrium, the development of the flange axial forces is greatly related to the development of transverse shear in the web. Figure 1e shows free-body diagrams for the top and bottom halves of the beam. Considering horizontal equilibrium in the free-body diagram, it is seen that the flange axial forces at the beam end are also associated with the development of longitudinal shear in the web. Therefore, considering the free-body diagrams in Figures $1 \mathrm{~d}$ and $1 \mathrm{e}$, the intensity of the flange forces and resulting stresses at the beam-column connection can be controlled by limiting the capacity of the web to carry transverse or longitudinal shear forces. Because typical steel beams have ample shear strengths compared with the shear demands, a relatively large portion of the web section must be removed to achieve this goal.

Openings (i.e., voids) can be introduced into the web of a wide-flange section beam to reduce the shear strength. By fabricating only one or two openings, the transverse shear strength of a beam may be reduced enough to form a mechanism involving relative vertical offsets that take place over the opening regions. This mechanism is designated as Mode-A in Figure 2a, and is mainly caused by local plastic hinging (in flexure) of the T-section beams above and below the openings. In contrast, for a beam having many openings in the web over the span, a greater reduction in the longitudinal shear capacity may be achieved compared to the transverse shear capacity, and this can lead to the formation of a mechanism showing relative horizontal offsets of the top and bottom portions of the beam. This mechanism is designated as Mode-B in Figure $2 \mathrm{~b}$, and is associated with local yielding and/or buckling of the "web posts" that exist between the adjacent openings. The web posts may be proportioned to deliver any desired level of stress to the beam-column connections, with the goal of limiting the stress in the connections to promote ductile behavior. Therefore, the mode of deformation of a RWS beam depends on the 
relative shear strengths and demands in the longitudinal and transverse directions.

The Mode-A mechanism in Figure 2a must be designed and detailed to be compatible with the floor slab on the RWS beam. If web openings producing this mode are located in a region subjected to gravity-induced shear forces, initial yielding is expected to occur at the locations where the shear due to lateral loads is additive with the shear due to gravity loads. Reversed cyclic excitations of earthquake loading would then cause a downward "ratcheting" of the beam, which would be expected to result in large downward residual deformations of the floor system. Such deformations can be minimized by positioning web openings at the locations where the gravity shear is expected to be small (i.e. near the beam midspan). Large deformations associated with the Mode-A mechanism would possibly cause a shortening of the beam, which if restrained to some degree by the floor system, would induce some tension into the beam.

The floor slab will undergo less deformation in the Mode-B mechanism, but some consideration should be given to the detail required for compatibility with the floor slab. Large deformations associated with the Mode-B mechanism cause a reduction in the depth of the beam segment (Figure 2b), which is kinematically incompatible with the beam-column connection that is expected to remain elastic or nearly so. To accommodate a change in the beam depth over the span, a flexible transition region may be provided by means of a large web opening adjacent to the connection, as illustrated in Figure 2b. The flexibility of the T-shape sections (above and below the opening) in the transition region accommodates this change in beam depth.

\section{Derivation of Strength Design Formulae for RWS Beams}

Figure 3 illustrates two free-body diagrams associated with the inelastic mechanisms that are assumed to develop in RWS beams (Figure 2). The Mode-A mechanism in Figure 3a will occur when two plastic hinges form in each of the non-prismatic T-beams above and below the web opening (Figure 2a). Detailed procedures to determine the beam shear associated with the ModeA mechanism can be found in the companion paper [19].

The Mode-B mechanism in Figure $3 b$ will occur when plastic hinges form in the web posts and in the T-sections above and below the opening located in the transition region (Figure $2 b$ ). The web posts may yield in shear or flexure, or a combination of the two, as illustrated in Figure 4. Given the geometry of the web post, any yielding of the web post in shear will occur at a critical section located along the beam centerline. Due to symmetry, the moment at this section in the web post is zero. An assumption of the Von Mises yield criterion results in the shear strength of the web post associated with shear yielding $\left(V_{w p, s}\right)$ to be: 


$$
V_{w p, s}=\frac{f_{y}}{\sqrt{3}}\left(s-d^{\prime}\right) t_{w}
$$

132 where $f_{y}$ is the yield stress of steel, $s$ is the center-to-center spacing of circular openings, $d$ ' is the 133 diameter of the openings, $t_{w}$ is the thickness of the web (Figure 5). Alternatively, yielding in 134 flexure may occur at locations equidistant above and below the beam centerline. Considering the usual distribution of normal stress (equal to $f_{y}$ ) over the plasticized section (and therefore, neglecting any influence of the non-prismatic nature of the web post) allows the shear strength of the web post associated with flexural hinging $\left(V_{w p, f}\right)$ to be determined as:

$$
V_{w p, f}=\frac{f_{y}}{2} \frac{\left(s-d^{\prime} \cos \theta\right)^{2} t_{w}}{d^{\prime} \sin \theta}
$$

where $\theta$ is the angle defining the position of the plasticized section, measured from the beam centerline (Figure 4). For a given web post geometry, the governing flexural hinging mechanism is obtained for the value of $\theta$ that minimizes $V_{w p, f}$. Whether a flexural hinging or shear yielding mechanism governs the web post depends on the value of $s / d$ '. Evaluation of Eq. (1) and Eq. (2) indicates that for values of $s / d$ ' less than approximately 1.27 , the relatively slender web post is governed by plastic hinging in flexure. For larger values of $s / d$ ', the governing mechanism is shear yielding. In the case of the Tresca yield criterion, the threshold value of $s / d$ ' changes to approximately 1.20 .

For preliminary design, the $s / d$ ' ratio may be used to establish the governing mechanism for the web posts. The shear force resisted by each web post can be obtained using Eq. (1) or (2) as applicable, or more directly, the minimum of the two equations. The free-body diagram of Figure $3 \mathrm{~b}$ indicates that axial forces at the T-sections in the transition region must equilibrate the total shear force in all web posts. The plastic moment strength of each T-section can be determined considering the expected axial compression or tension force. Although there are four such T-sections (in two transition regions) for a given RWS beam, due to rotational symmetry (for a rotation of $180^{\circ}$ ), there are only two unique cases to consider: one in which bending moment and axial force both contribute to compression in the flange portion of the T-section, and one in which bending moment and axial force both contribute to tension in the flange portion of the T-section. Because we assume that the plasticized T-section yields in tension and compression at the same stress $f_{y}$, these two cases are equivalent except for sign.

For analysis, consider the T-section above the leftmost opening in Figure 3b, which is illustrated in Figure 5a. The terms $d_{T}$ and $y_{P N A}$ are defined as the depth of the T-section and the depth from the top of the T-section to the plastic neutral axis, respectively. If the plastic neutral 


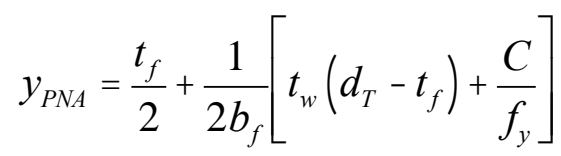

164 where $t_{f}$ is the flange thickness, $b_{f}$ is the flange width, $t_{w}$ is the web thickness, and $C$ is the axial 165 force (positive in compression) acting at the centroid (located a distance $c$ from the top) of Tsection together with the moment $M_{T}$ to cause compression in the flange. Thus, neglecting the possible minor influence of shear on the plastic moment capacity of the T-section, the plastic moment that develops in the T-section $\left(M_{T}\right)$ is given by:

$$
\left.M_{T}=\frac{f_{y}}{2}\left[b_{f}\left(2 y_{P N A}\left(2 c \quad y_{P N A}\right) \quad t_{f}\left(2 c \quad t_{f}\right)\right)+t_{w}\left(\begin{array}{llll}
d_{T}^{2} & t_{f}^{2} & 2 c\left(d_{T}\right. & t_{f}
\end{array}\right)\right)\right]
$$

\section{0}

where $A_{w}=\left(d_{T}-t_{f}\right) t_{w}$ (the web area of one T-section) and $C_{v}$ is a coefficient defined by Segui [20].

Alternatively, if the plastic neutral axis is within the web $\left(y_{P N A}>t_{f}\right)$, horizontal equilibrium requires:

$$
y_{P N A}=\frac{1}{2}\left[d_{T}+t_{f}\left(1 \frac{b_{f}}{t_{w}}\right)+\frac{C}{f_{y} t_{w}}\right]
$$

with the corresponding plastic moment given by:

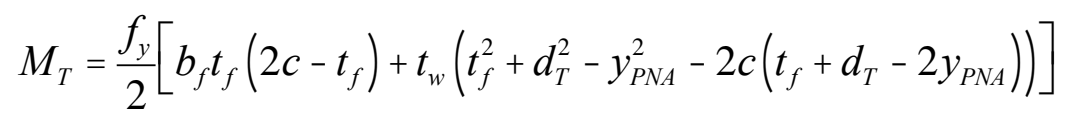

Thus, for a given web post design, the axial force at the T-section in the transition region can be determined, along with the moment when the T-section plasticizes. With reference to Figure 5b, the transverse beam shear $\left(V_{v}\right)$ associated with this mechanism occurring at all four T-sections in the two transition regions can be determined as:

$$
V_{v}=\frac{2 C d+\sum M_{T}}{L^{\prime}}
$$

where $L^{\prime}$ is the distance between the two plastified sections of the beam, $d$ is the distance between the geometric centroids of the top and bottom T-sections, and $\Sigma M_{T}$ is the sum of all four T-section moments (see Figure 5). The geometry of the openings is such that the shear calculated in Equation 7 will rarely, if ever, exceed the shear strength of the T-sections. As a capacity limit, we may impose an upper limit on the shear carried by the pair of T-sections equal to

$$
V_{n}=2\left(0.6 A_{w} f_{y} C_{v}\right)
$$

Using this approach, the geometry of the web openings can be established to create a mechanism 
that limits the level of shear force developing in the beam, so as to limit the stress in the beamcolumn connections.

Of particular concern in the design of the Mode-B specimens (Specimens 2 to 5) was the potential buckling of the web posts, which would greatly reduce the strength and ductility of the beam. Slender web posts would contribute to the deformation capacity of the beam, but would be more susceptible to buckling. Figure 6 illustrates a simple strut and tie idealization of the forces carried by a web post. The diagonal tensile and compressive forces transmit a constant shear force. The buckling of the compression strut would be restrained by the tension tie, so that a buckling mode would involve a double curvature with a node located close to the mid-depth of the beam (Figure 6). While the concept is simple, the evaluation of the buckling load would require a rigorous geometric characterization of the non-prismatic compressive strut as well as the restraints provided over the span and at the ends of the hypothesized strut. This is beyond the scope of the present study.

\section{Experimental Program}

In this study, ten approximately full-scale beam-column frame specimens were tested subjected to quasi-static cyclic lateral loading often used for earthquake-related testing. Each frame specimen consisted of a wide-flange beam having a unique reduced-web configuration, and a beam-column connection and stub column at each end of the beam (Figure 7). Various web opening geometries (Figure 8) were explored to discover inelastic mechanisms that achieve ductile behavior prior to the incident of significant inelastic deformation at the beam-column connections.

The experimental program proceeded in two phases. Mode-B behavior was emphasized in Phase 1, which consisted of Specimens 1 to 5 in Figure 8, and Mode-A behavior was emphasized in Phase 2, which consisted of Specimens 6 to 10. This paper focuses on the test results of Phase 1, while a companion paper [19] focuses on those of Phase 2.

\subsection{Design of Phase 1 Specimens}

The Phase 1 specimens were designed aiming at identifying primary behavioral characteristics associated with Modes A and B, such as strength, deformation capacity, failure mode, and type and onset of instability. Table 1 summarizes design details and variables of the five specimens tested in Phase 1, and Figure 8 presents web opening geometries in the specimens. A W21×68 (Grade 50) shape was used for all five specimens, so that the effects of web opening geometry 
would be readily evident. The W21x68 shape was selected recognizing both the nominal 100kip limit of the hydraulic actuator at the test lab and a desire to have a shape of realistic depth. The relatively slender shape would, therefore, tend to promote potential instabilities. Specimen 1 was designed to investigate the Mode-A mechanism, while Specimens 2 to 5 were designed to investigate the Mode-B mechanism.

The web openings were proportioned initially assuming potential inelastic mechanisms on the basis of aforesaid plastic mechanism analyses using Eq. (1) to (7); the designs were subsequently validated using detailed nonlinear finite element analysis (FEA). For the design of Specimen 1, the free-body diagram in Figure $3 \mathrm{a}$ was considered, and for the design of Specimens 2 to 4 , the diagram in Figure $3 b$ was considered. The story shears associated with the assumed plastic mechanisms are calculated and summarized in Table 4.

In all five specimens, the two openings nearest the beam-column connections were similar in diameter: 419 or $406 \mathrm{~mm}$ (16.5 or $16 \mathrm{in}$.), and also the center-to-center distance between the two openings was almost the same: 2.06 or $2.03 \mathrm{~m}$ (81 or 80 in.). Among Specimens 2 through 5, the web post configurations were varied to understand effects of the dimensions and slenderness of web posts on the failure mode, type and onset of instability, strength, and ductility of the beams.

- Specimen 1 had only two widely separated circular openings with a diameter of 419 $\mathrm{mm}(16.5$ in.) near the beam-column connections.

- Specimen 2 had five circular openings with a diameter of $406 \mathrm{~mm}$ (16 in.). The web posts had the slenderness ratio of about 1.27 (Table 1), so they were expected to experience flexural hinging and shear yielding by similar degrees according to the Von Mises yield criterion (Figure 4).

- Specimen 3 had seven circular openings. The five interior openings had a $254 \mathrm{~mm}$ (10 in.) diameter. The web posts were the most slender among the specimens and expected to yield in flexure according to the Von Mises yield criterion (Figure 4a).

- Specimen 4 had five openings. The three interior openings had a length of $406 \mathrm{~mm}$ (16 in.) like Specimen 2, but they had a "racetrack" configuration using semicircular ends with a diameter of $203 \mathrm{~mm}$ ( $8 \mathrm{in}$.). The web posts had the slenderness ratio of about 1.52 (Table 1) and were expected to yield in shear (Figure 4b).

- Specimen 5 had five openings like Specimen 4. The three "racetrack" openings had the same length as those in Specimen 4, but were narrower. The web posts were the stockiest among the specimens and expected to yield in shear (Figure 4b). 
All beam-column connections were made with welded unreinforced flanges with bolted webs, following the design details for the WUF-B connection of FEMA-350 [1]. Continuity plates were provided in the stub columns; doubler plates were not provided because standard design calculations indicated they were not needed. For the beam top flange connection, the weld backing bar remained in place; a reinforcing fillet weld was added between its underside and the column flange. For the beam bottom flange connection, the weld backing bar was removed, the bottom flange root weld was gouged out, and a reinforcing fillet weld was added between the weld material and the column flange. The weld material was notch-tough, with a specified minimum Charpy V-Notch $(\mathrm{CVN})$ of $27 \mathrm{~N}-\mathrm{m}(20 \mathrm{lb}-\mathrm{ft})$ at $-20{ }^{\circ} \mathrm{F}\left(27 \mathrm{~N}-\mathrm{m}\right.$ at $\left.-29^{\circ} \mathrm{C}\right)$. The connections were welded by certified welders in their field orientations, with the columns vertical and beams horizontal.

\subsection{Material Properties}

In Phase I, a single steel shape W21×68 was used for the beam specimens. The steel shape was produced from two heats. For each heat, test coupons were obtained from the web as well as the flange. Table 2 reports the results from the tension tests of the coupons, and Table 3 shows the manufacturer's mill test data.

For the Phase 1 specimens, two coupons were obtained from the flange and two from the web of an extra beam segment from each heat group. The coupons were $38.1 \mathrm{~mm}$ (1.5 in.) wide and had a gage length of $203.2 \mathrm{~mm}$ (8 in.), conforming to ASTM A370 [21]. The longitudinal axis of the coupons was parallel to the longitudinal axis of the beam. The web coupons were taken at least $50.8 \mathrm{~mm}$ ( 2 in.) away from the " $\mathrm{k}$ " line of the section, and the flange coupons were taken from the flat portion of the flange away from the web-to-flange fillet.

The tension tests of the steel coupons were conducted following ASTM A370 [21]. The upper and lower yield points were determined from the recorded stress-strain data, as were the modulus of elasticity, modulus of strain hardening, strain at the onset of strain hardening, and total elongation. The modulus of elasticity was determined using the method of least squares, up to a stress equal to $80 \%$ of the upper yield point stress. The modulus of strain hardening, $E_{s t}$, and strain at the onset of strain hardening, $\varepsilon_{s t}$, were calculated as follows. First, the center of the dip in the stress-strain curve at the onset of strain hardening was determined. Then, points on the stress-strain curve were established at strains equal to 0.003 and 0.010 beyond the center of the 
the onset of strain hardening was defined by the intersection of this line with the yield plateau.

\subsection{Specimen Fabrication}

292 The specimens were fabricated by Ozark Steel Fabricators, Inc. in Farmington, Missouri, USA.

293 The web openings in the beams were cut using a Peddinghaus Corporation CNC Structural Steel

294 Burning System. The burning process used a torch that followed a predefined, computer-

295 controlled path to cut out the openings. The torch typically left a small notch in the steel at the initial point of entry. The notch locations were chosen carefully to be in regions of relatively low inelastic demand, so that the small notches would not cause adverse behavior in the tests. The reduce web-section beam portion was welded to the stub columns (W14×176 in Phase 1) of each specimen by the fabricator.

300

\subsection{Test Setup and Loading Sequence}

303

304

The loading frame consisted of a top beam, a base beam, and two columns, as shown in Figure 7. The top beam was made of TS $14 \times 10 \times 5 / 8$, the base beam was made of TS $16 \times 12 \times 5 / 8$, and the columns were $\mathrm{W} 14 \times 176$ shapes. The top and bottom of each loading frame column were pinconnected to the top and base beams using 50.8-mm (2-in.) diameter steel pins. The center-tocenter distance between the pins was $4.50 \mathrm{~m}$ (177 in.) horizontally and $3.15 \mathrm{~m}$ (124 in.) vertically. A hydraulic actuator was attached to one end of the top beam into the horizontal direction.

The loading frame was designed to experience negligible deflections in the tests when loaded to the capacity of the actuator. The loading frame performed well, except that some slip between the base beam and the floor was observed in the test of Specimen 1. No slip occurred after additional anchor bolts were installed to better anchor the base beam. Also, the loading frame was cycled without a specimen present to check the resistance of the frame itself to lateral displacements. In this test, actuator forces did not exceed $3 \mathrm{kN}(0.7 \mathrm{kips})$ at story drifts up to $\pm 10 \%$.

The H-shaped beam-stub column frame specimen was to be fit within a clear distance of $4.11 \mathrm{~m}$ (161-3/4 in.). With the presence of the stub columns (W14×176 in Phase 1), which were welded to the tested beam by the fabricator, the beam clear span was $3.33 \mathrm{~m}(131-1 / 4 \mathrm{in}$.) for the Phase 1 tests. The H-shaped frame specimens were bolted to the loading frame columns. The specimens themselves were not braced laterally, but the top beam of the loading frame was guided against out-of-plane motion by means of Teflon-padded beam stubs near its ends, which 


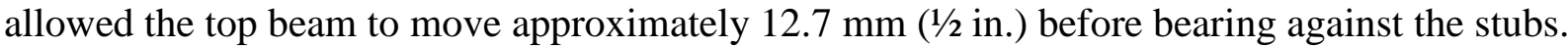

Quasi-static reversed cyclic loading in Figure 9 was applied following the modified SAC loading protocol by the actuator attached to the top beam. The story drift is defined as the actuator displacement divided by the vertical distance between the top and bottom pins. Because the loading frame and stub columns together created almost rigid elements, the tested beam underwent a larger chord rotation for a given story drift than in a real building system, where columns having greater flexibility would also contribute to the total story drift. Therefore, story drifts in real buildings corresponding to a certain level of damage in the tested beams would be somewhat larger than the story drifts reported herein.

\section{Pre-Test Nonlinear Finite Element Analysis}

Prior to finalizing the web opening details, nonlinear finite element analyses (FEA) were conducted for the five specimens as well as a control specimen (designated "Unperforated W21×68”) having the same shape beam with no web openings. These analyses were done using ABAQUS software to verify the assumed inelastic mechanisms (Figure 2) and to estimate the yield strengths of the specimens. The nominal specimen dimensions shown in Figure 8 were considered, and the clear span length between the faces of the stub columns was taken as 3350 mm (132 in.). The Abaqus element C3D20R (20-node quadratic solid element with reduced integration) was used throughout each model. A bilinear stress-strain relationship was assumed for the steel, with the yield strength of $379 \mathrm{MPa}$ (55 ksi), elastic modulus of $200 \mathrm{GPa}(29,000$ ksi), and post-yield (strain-hardening) modulus of $1.38 \mathrm{GPa}$ (200 ksi). At this stage, no attempt was made to simulate fracture.

To simulate only the beam of Figure 7 in the numerical model, one end of the beam was fully restrained against both translation and rotation, while the other end was released for translation only in the direction transverse to the longitudinal axis of the beam. Then, loading was applied along the released direction at this end. Since there was no attempt to model instability (e.g., buckling, fracture), no initial out-of-straightness was modeled.

Figure 10 plots the computed story shear-story drift responses of the specimens; based on the geometry of the loading frame in Figure 7, the story shear is taken as 1.43 times the beam shear acquired from the FEA, and the story drift is taken as the beam chord rotation divided by 1.34 , in which the chord rotation is the transverse displacement divided by the clear span length of the beam.

Of the RWS beams, Specimen 1 in the Mode-A mechanism shows the highest yield 
strength, while Specimen 3 with the most slender web posts shows the lowest yield strength. Among the specimens with five openings at the same spacing, the specimen having the more slender web posts exhibits the smaller yield strength. It should be noted that out-of-plane buckling of the web posts and fracture of the web was not modeled and could substantially affect the strengths of the specimens in the inelastic range of behavior.

According to the FEA results, yielding initially occurs in the webs around the edges of the openings in Specimen 1, while it happens in the web posts in all other specimens. As shown in Figure 11, the inelastic mechanism of Specimen 1 is governed by the development of plastic hinges in the T-beams above and below each web opening (Mode-A in Figure 2a); each T-beam deforms in a double curvature. In contrast, the overall behaviors of Specimens 2 to 5 are considered each as a hybrid between a diagonal truss consisting of tension ties and compression struts acting through the web posts, and a Vierendeel truss [22] inducing bending of the T-beams above and below the openings (Mode-B in Figure 2b).

Figure 12 illustrates the deformed shape of web posts at $5 \%$ beam chord rotation from the FEA for each of Specimens 2 to 5, in which maximum principal stresses are plotted together. It is shown that the web posts in Specimen 3, which are the most slender, are affected by flexural deformation by the greatest degree. In contrast, the web posts in Specimens 4 and 5 are governed mostly by shear deformation. With regard to the distribution of maximum principal stresses, tension ties acting through the web posts are clearly identified in all four specimens. The sides of circular edges of the openings are straightened out, which is likely due to the action of the tension ties.

\section{Test Results}

\subsection{Overall Load-Drift Response and Damage}

Figure 13 shows the hysteretic story shear-story drift responses of the five specimens tested in Phase 1, and the envelope curves constructed connecting the maximum drift point of the first cycle to each drift level. The yield point in the experimental load-drift curve is defined based on ATC 24 [23] and FEMA-289 [24], at the intersection point between the secant of the envelope curve from the origin to the point of $75 \%$ the maximum load and the horizontal line passing through the maximum load. Table 5 summarizes the story shears and story drifts at the maximum load and yield points in each test, and the maximum story shear $V_{\max }$ is compared with the story shear computed based on the assumed plastic mechanism, $V_{\text {Mises }}$ or $V_{\text {Tresca }}$. Here, $V_{\text {Mises }}$ and $V_{\text {Tresca }}$ are determined using the Von Mises yield criterion and Tresca yield criterion, 
respectively. In general, the $V_{\max }$ values are in good agreement with the $V_{\text {Mises }}$ or $V_{\text {Tresca }}$ values: the average of $V_{\text {Mises }} / V_{\max }$ values is 1.08 and the average of $V_{\text {Tresca }} / V_{\max }$ values is 0.97 . Note that the assumed plastic mechanisms result in almost the same story shears for Specimens 2, 4, and 5 with the same details except the height of the interior openings, while the maximum loads reached in the tests were affected by variation in the slenderness ratio of web posts. This is in part because the plastic analyses do not take into account flexure-shear interaction in the web posts.

Figure 14 presents the deformed shapes of the specimens; each picture was taken near the end of testing. The deformed shapes clearly indicated that Specimen 1 developed the ModeA mechanism in Figure 2a, while Specimens 2 to 5 developed the Mode-B mechanism in Figure $2 b$, as predicted in the FEA results. Also, the deformed shapes of web posts observed in the tests were similar to those acquired from the FEA (Figure 12).

Specimen 1 in Figure 13a was loaded up to approximately 3\% story drift in the push (-) direction, and the maximum lateral load was approximately $578 \mathrm{kN}$ (130 kips). This specimen achieved the highest maximum load among the five specimens in Phase 1, which is in agreement with the FEA results (Figure 11). However, the maximum drift in the pull (+) direction was limited to less than $1.2 \%$ because the actuator load capacity in that direction was only $423 \mathrm{kN}$ (95 kips). Data collection was further impaired by the actuator calibration prior to the test, in which the maximum recordable force had been set to $445 \mathrm{kN}$ (100 kips). Although the test did not continue up to failure due to the aforesaid reasons, Specimen 1 exhibited excellent performance over the entire range of applied drifts. The load-drift hysteretic loops were very stable with no strength degradation or pinching by the end of testing (Figure 13a). Neither buckling nor fracture occurred in any part of the specimen, and no yielding was detected in the connection panel zones.

In Specimen 2 (Figure 13b), inelastic load-drift behavior became apparent from about $1 \sim 1.5 \%$ drift when yielding occurred in the web posts as well as in the webs around the outermost openings. The peak story shear strength of Specimen 2 was approximately $338 \mathrm{kN}(76.0$ kips), much smaller than that of Specimen 1. Soon after the inelastic mechanism started to develop, all the web posts buckled out-of-plane in an "S-shaped" double curvature. (Figure 2b suggests that the beam flanges moving closer to each other may enforce buckling of the web posts.) The web post buckling started from the $1.5 \%$ drift cycles, and all buckled by the $2 \%$ drift cycles. Associated with the web buckling, there was a sudden drop larger than $25 \%$ in the lateral strength. Nevertheless, the lateral strength of Specimen 2 remained stable at around $222 \mathrm{kN}$ (50 kips) up to $6 \%$ story drift. 
Continued cyclic loading in Specimen 2 caused cracks at the buckled web posts, as they were forced to straighten out (although they never came to be completely straight). These cracks resulted in brittle fracture of the web posts in subsequent larger drift cycles. The cracks in the web posts were first observed during the $5 \%$ drift cycles, and completely separated all web posts during the $7 \%$ drift cycles. Due to the web post fracture, the load-drift hysteretic loops changed from a full to S-shaped pattern (Figure 13b), which indicates a lower energy dissipation capacity. The load-drift curves also showed gradual degradation in the unloading and reloading stiffnesses. Despite the loss of the web posts, however, the strength of the specimen was reduced only by approximately $10 \%$ up to $8 \%$ story drift.

Specimen 3 exhibited the least ductile load-drift behavior among the Phase I specimens (Figure 13c). In Specimen 3, inelastic load-drift behavior initiated at a smaller drift than in Specimen 2. The peak strength of Specimen 3 was approximately $310 \mathrm{kN}$ (69.8 kips), the lowest among the five Phase 1 specimens, which well matches with the FEA results (Figure 11). Like in Specimen 2, the web posts of Specimen 3 buckled in an S-shaped double curvature during the $1.5 \%$ and $2 \%$ drift cycles, drawing in and rotating the flanges. After the web buckling, the lateral strength reduced by approximately $23 \%$ from 310 to $240 \mathrm{kN}$ (70 to $54 \mathrm{kips}$ ), and it remained only up to $3 \%$ story drift. Then, point cracks occurred in the web posts during the $3 \%$ drift cycles, and all web posts completely fractured by $4 \%$ story drift, which was the earliest among the five specimens. As the web posts fractured one by one, the strength of the specimen decreased substantially, to below $89 \mathrm{kN}$ (20 kips).

The load-drift hysteretic loops of Specimen 3 remained full through the 3\% drift cycles, but after the web fracture, the loops became narrower with much reduced stiffness (Figure 13c). The beam flanges, which had been pulled towards each other by the buckling of the web, were observed to straighten out during the 5\% drift cycles. After completing the $7 \%$ drift cycles, Specimen 3 was displaced monotonically to over $11 \%$ drift. The lateral strength of the system almost fully recovered reaching $289 \mathrm{kN}$ (65.0 kips) at the time when the test was halted due to visible bending of the pins at the base of the loading frame. The strength recovery appeared to be owing to second-order geometric effects associated with elongation of the beam between the plastic hinges in the two transition regions near the connections (refer to Figure $2 b$ ).

The overall responses of Specimens 4 and 5 in Figures $13 \mathrm{~d}$ and 13e were similar to that of Specimen 2, except that Specimens 4 and 5 presented larger stiffnesses at the early stage. The cyclic load-drift responses were reasonably stable up to the first cycle to $6 \%$ drift in both specimens. The peak load was approximately $402 \mathrm{kN}$ (90.4 kips) and $426 \mathrm{kN}$ (95.7 kips) in Specimens 4 and 5, respectively. The web posts buckled out-of-plane during the $2 \%$ or $3 \%$ drift 
cycles. During the 2\% drift cycles in Specimen 5, the load and imposed drift in the pull (+) side were limited by the actuator load capacity in that direction, while the load in the push (-) side reached approximately $454 \mathrm{kN}$ (102 kips). Then, major buckling of the web posts happened during the first cycle to $3 \%$ drift. This caused a strength reduction and allowed this and subsequent cycles to be completed within the capacity of the actuator (Figure 13e).

The web post buckling induced a sudden drop in the lateral load of about $26 \%$ and $22 \%$ in Specimens 4 and 5, respectively. However, the reduced strength carried by the buckled shape was maintained until the first cycle to $6 \%$ drift in both specimens (Figures 13d and 13e). Fracture of the web posts initiated in the second $6 \%$ or first $7 \%$ drift cycle, and most fractures occurred during the $7 \%$ drift cycles. As a result, a significant reduction in the lateral strength and stiffness happened, and the hysteretic load-drift loops became flat and pinched afterward.

\subsection{Effects of Web Post Yielding, Buckling, and Fracture on Strength and Ductility}

Buckling had a much greater influence on the performance of the Mode-B specimens (postyield), than the Mode-A specimens (Specimen 1 and specimens described in the companion paper [19]). For the specimens with web posts (that developed the Mode-B mechanism), peak strength was controlled by the yielding of the posts; buckling of the web posts began only after the posts had yielded. Buckling of the web posts resulted in a reduction in load resistance as well as a concentration of strain that ultimately led to fracture (due to low-cycle fatigue) of the posts. Once the web posts had fractured, the hysteretic loops of the Mode-B specimens became Sshaped, with comparatively little hysteretic energy dissipation.

Among Specimens 2, 4, and 5, which had the same details but with varied interior opening heights (Figure 4), the specimen with the more slender web posts exhibited the smaller peak strength, as predicted in the FEA results (Figure 11). This likely was because the more slender web post would be subjected to the greater normal stresses due to flexure for a given shear force; the web posts in Specimen 2 had a plastic mechanism governed by flexure, while those in Specimen 5 were governed by shear (see Figure 6). Similarly, Specimen 3 that achieved the lowest peak strength among the Phase I specimens had the most slender web posts, as well as the smallest total section area along the beam centerline.

In all four specimens with web posts (Specimens 2 to 5), web post buckling occurred at similar drifts (i.e., 1.5 to $2 \%$ ) regardless of the web post slenderness ratio (Table 1). This likely was because a larger load was applied to the specimen with the stockier web posts at the event of the buckling. Also, the percentage of strength drop associated with web post buckling was similar (i.e., 22 to $26 \%$ ) in all four specimens. 
The fracture of web posts was the most severe in Specimen 3, which occurred during the $3 \%$ and $4 \%$ drift cycles and resulted in the largest strength drop among the four specimens with web posts; this specimen had the most slender web posts. In contrast, the other three specimens (Specimens 2, 4, and 5), which had the same details but with varied interior opening heights, suffered the web post fracture during the $6 \%$ and $7 \%$ drift cycles. It is noted that Specimen 2 retained a larger residual strength than Specimens 4 and 5 after suffering the web post facture, although Specimen 2 had more slender web posts than Specimens 4 and 5 and achieved smaller peak strengths.

\subsection{Strains at Connections and around Openings}

Each of the five Phase 1 specimens was instrumented with a total of 28 to 43 electrical resistance strain gages. Gauges were attached with epoxy adhesive to surfaces that had been sanded with coarse-grit sandpaper to enhance adhesion of the epoxy at large strains. Nevertheless, our confidence in the accuracy of the recorded data diminishes as the number of cycles and amplitude increase. Values exceeding perhaps $0.005-0.01$ are considered to be only an indication of overall trends. Figure 15 shows the locations and labels of strain gages installed in the specimens. Strain rosettes were installed at the spots where principal and/or shear strains were of interest. Each rosette consisted of three gages that were arranged in the horizontal, vertical, and 45-degree directions, indicated by three numbers in order in Figure 15. Principal strains are calculated using normal strains acquired from the three gages at each measurement step. At each rosette, the onset of yielding is judged by whether the major principal strain exceeded the yield strain of the steel or not. In general, the strain data suggest that the nonlinear responses of the specimens were primarily attributed to the yielding of web posts (if any), as well as web portions around and T-beams above or below the openings closest to the beamcolumn connections.

In all five Phase 1 specimens, no yielding occurred in the flanges near the beam-column connections, based on strain data acquired from gages \#1 to \#3 and \#7 to \#9 (see Figure 15 for the locations), as shown in Figure 16. Assuming a linear moment distribution along the beam span, the strains at the connection welds were deemed to remain below the yield strain of the steel throughout the tests. In contrast, the top flange directly above the leftmost web opening started to yield at about 3 or $4 \%$ drift in Specimens 2 to 5, while this flange portion did not yield in Specimen 1 due to test hardware limitations. This indicates that the basic capacity design principle in which openings are introduced in the web can be used to limit the level of stress at the connections by inducing plastic hinges within the beam. 
The web portion just below the top flange above the leftmost or rightmost opening yielded at about 2 or $3 \%$ drift in all specimens, except that the web above the rightmost opening in Specimen 2 yielded earlier at $1.0 \%$ drift. This is assessed based on the history of principal strains calculated using data from four strain rosettes in each specimen (Figure 17 for gages \#14 to \#22 and one rosette above the rightmost opening). For the instrumented regions, Specimen 5 yielded at a larger drift (i.e., 3\%) compared with the other specimens.

Strain data in the web around the leftmost opening were measured using gages \#10 to \#13 (see Figure 15 for the locations), which were installed tangential to the perimeter of the opening. The web around the leftmost opening started to yield at about 1 or $1.5 \%$ drift in the specimens. For the instrumented regions, yielding developed slightly earlier in Specimens 1 and 5, which either lacked web posts or had the stockiest web posts in all five specimens. Due to the geometric symmetry, a similar behavior is assumed to have occurred in the web around the rightmost opening.

\subsection{Strains at Web Posts}

Web post behavior was evaluated using data acquired from a strain rosette installed at the mid-height of the post. Figure 18 illustrates the principal strain histories at all web posts (see Figure 15 for the rosette locations). In Specimens 2 to 5, the web posts underwent yielding from about 0.75 or $1 \%$ drift, earlier than the other web or flange portions did. Among the web posts of each specimen, no trend is identified for which web posts suffered from earlier onset or greater severity of inelastic deformation. Although there was no web post in Specimen 1, one strain rosette (gages \#23 to \#25) was installed at the same location as that of the leftmost post in the other specimens for comparison. This web portion in Specimen 1 yielded at about 2 3\% drift, which was much later than for the other specimens and also happened after the webs and flanges around the openings of Specimen 1 had yielded.

Table 6 summarizes the approximate story drift at which each portion of each specimen first yielded. Based on the results, all five specimens were well proportioned in that the level of stress at the beam-column connections appeared to remain below the yield point of the steel (see Figure 16). In Specimens 2 to 5, yielding occurred first in the web posts, and at larger drifts it extended sequentially to the webs around the edges of the outmost openings, the webs above and below, and the flanges above and below the openings closest the connections, which indicates the development of plastic hinges in the T-beams. This implies that the nonlinear load-drift responses of the specimens having web posts initiated primarily from the yielding of the web posts, and they developed the Mode-B mechanism. In contrast, the first yielding in Specimen 1 
happened in the webs around the leftmost and rightmost openings away from the centroidal axis of the beam. The progress of inelastic mechanism in Specimen 1 was limited because of the incomplete termination of the test.

\section{Conclusions}

From the experimental, analytical, and numerical investigations of the Phase One specimens detailed herein, significant findings and conclusions are summarized as follows:

1. The application of web openings is a successful capacity design strategy to limit stresses at the beam-column connections. The specimens illustrated the development of the intended Mode-A or Mode-B mechanisms. The test data demonstrated that the strength of the RWS specimens having Mode-B mechanisms was reduced at story drifts of around 5\%, although the specimens were able to sustain story drifts of at least 8\%. Due to test hardware limitations, large drifts could not be imposed on the specimen having a Mode-A mechanism; results for other Mode-A specimens are described in a companion paper [19].

2. The sequence of yielding in the Mode-B specimens consisted of yielding of the web posts (at story drifts of 0.75 to $1 \%$ ), yielding at the peripheries of the largest web openings, closest to the beam column connections (at story drifts of about $1.5 \%$ ), yielding of the webs above and below the largest openings (generally around $2 \%$ story drift), followed by yielding of the flanges above and below the largest openings (generally around $3 \%$ story drift). Details are provided in Table 6.

3. The web posts of the Mode-B specimens buckled out-of-plane at story drifts of 1 to $1.5 \%$. Buckling initiated only after the web posts yielded, and appeared to be induced by kinematically-prescribed movements of the flanges associated with the mechanism of Figure $2 b$. Web post buckling caused a reduction in lateral resistance of between 21 and $33 \%$. The post-buckled strengths were maintained to story drifts of 5 to $6 \%$. Buckling of the stockier web posts (Specimens 4 and 5) was associated with a lesser reduction in strength than buckling of the more slender web posts (Specimens 2 and 3). However, the stockier web posts of Specimen 5 fractured in the 6\% story drift cycles, while the more slender web posts (of Specimens 2 and 4) fractured only after the $6 \%$ cycles. The narrow web posts of Specimen 3 fractured at smaller drifts. The web posts 
fractured by ductile tearing, and the gradual failure of a post had a small effect on the lateral resistance, because load transfer could be maintained by other web posts acting in parallel.

4. Simple analytical approaches used to size web openings to achieve the Mode-B plastic mechanisms, as detailed in this paper, were effective in achieving the intended mechanisms. Mechanisms determined by monotonic nonlinear finite element studies confirmed those determined using simple design methods and observed empirically.

5. The web post slenderness ratio, s/d', provides a useful index of the tendency towards flexure- or shear-dominated behavior of the web post. While analysis suggests a change from shear-dominated to flexure-dominated behavior as s/d' descends below 1.20 or 1.27 (depending on whether the Tresca or Von Mises yield criterion is used), the finite element and experimental studies suggest a more gradual transition between these discrete modes. Inspection of Figure 3 shows that flexural deformations are present in the deformed shape of Specimen 3, which has an s/d' equal to 1.23; shear deformations become more dominant as s/d' values increase to 1.27 (Specimen 2), 1.52 (Specimen 4), and 2.00 (Specimen 5).

6. Plastic strengths predicted by application of the Von Mises yield criterion to the web posts in conjunction with a Mode-B mechanism tended to exceed the empiricallydetermined strengths, which may have been increased by strain hardening. The correlation of these mechanism strengths with the maximum strengths evinced in the tests seem to be a function of the point at which instability of the web posts developed (Table 5).

\section{Acknowledgements}

The authors are especially grateful to B. Dodds, J. Gambill, and W. Gordon, whose generous assistance proved invaluable, and the use of facilities at the Construction Engineering Research Laboratory (Champaign, Illinois) under the adroit direction of J. Hayes. This work was primarily supported by the National Science Foundation under Grant No. CMS-9812465. Support from Ulsan National Institute of Science and Technology (UNIST) and Santa Clara University also is appreciated. Any opinions, findings and conclusions or recommendations expressed in this 
material are those of the authors and do not necessarily reflect those of the sponsor or the individuals or institutions identified above.

\section{References}

1. Federal Emergency Management Agency (FEMA). (2000). Recommended seismic design criteria for new steel moment frame buildings. FEMA, Washington, DC.

2. SAC Joint Venture. (2000). Recommended seismic evaluation and upgrade criteria for welded steel moment frame buildings (FEMA 351). FEMA, Washington, DC.

3. Chen, S. J., Yeh, C. H., and Chu, J. M. (1996). Ductile steel beam-to-column connections for seismic resistance. Journal of Structural Engineering, American Society of Civil Engineers, 122(11), 1292-1299.

4. Civjan, S. A., Engelhardt, M. D., and Gross, J. L. (2000). Retrofit of pre-Northridge moment-resisting connections. Journal of Structural Engineering, American Society of Civil Engineers, 126(4), 445-452.

5. Engelhardt, M. D., and Sabol, T. A. (1998). Reinforcing of steel moment connections with cover plates: benefits and limitations. Engineering Structures, 20(4), 510-520.

6. Uang, C. M., Bondad, D., and Lee, C. H. (1998). Cyclic performance of haunch repaired steel moment connections: experimental testing and analytical modeling. Engineering Structures, 20(4), 552-561.

7. Uang, C. M., and Bondad, D. M. (1996). Static cyclic testing of pre-Northridge and haunch repaired steel moment connections (Vol. 96, No. 2). Division of Structural Engineering, University of California, San Diego.

8. Chi, B., and Uang, C. M. (2002). Cyclic response and design recommendations of reduced beam section moment connections with deep columns. Journal of Structural Engineering, American Society of Civil Engineers, 128(4), 464-473.

9. Jones, S. L., Fry, G. T., and Engelhardt, M. D. (2002). Experimental evaluation of cyclically loaded reduced beam section moment connections. Journal of Structural Engineering, American Society of Civil Engineers, 128(4), 441-451.

10. Aschheim, M. A. (2000). U.S. Patent No. 6,012,256. U.S. Patent and Trademark Office, Washington, DC.

11. Darwin, D. (1990). Steel and composite beams with web openings: design of steel and composite beams with web openings (Design Guide 2). American Institute of Steel Construction. 
12. Sherbourne, A. N. (1966). The plastic behaviour of castellated beams. In Proc. 2nd Commonwealth Welding Conference (Vol. 2, pp. 1-5). Institute of Welding, London.

13. Halleux, P. (1967). Limit analysis of castellated steel beams. Acier-Stahl-Steel, 32(3), 133144.

14. Redwood, R., and Demirdjian, S. (1998). Castellated beam web buckling in shear. Journal of structural engineering, American Society of Civil Engineers, 124(10), 1202-1207.

15. Ward, J. K. (1990). Design of composite and non-composite cellular beams. Steel Construction Institute.

16. Lawson, R. M., and Hicks, S. J. (2011). Design of Composite Beams with Large Web Openings: In Accordance with Eurocodes and the UK National Annexes. Steel Construction Institute.

17. ArcelorMittel Europe. (2014). Sections and Merchant Bars Sales Programme, available at http://sections.arcelormittal.com/fileadmin/redaction/4-Library/1accessed April 5, 2016).

18. Goel, S. C., Leelataviwat, S., and Stojadinovic, B. (1997). Steel moment frames with ductile girder web opening. Engineering Journal, American Institute of Steel Construction, 34(4), $115-125$.

19. Shin, M., Kim, S.-P., Halterman, A., and Aschheim, M. A. (in review) Seismic toughness

20. Segui, W. T. (1998). Web shear strength of flexural members. Engineering Journal, American Institute of Steel Construction, 35(2), pp. 76-79.

21. American Society for Testing and Materials (ASTM). (2000). ASTM A370: Standard Methods and Definitions for Mechanical Testing of Steel Products. ASTM, West Conshohocken, PA.

22. Fu, C., Jiang, Y., and Liang, S. (2004). Experimental study on bearing capacity and seismic behavior of large-span two-storied Vierendeel truss transfer structure. Journal of Building Structures, 25(1), 36-44.

23. Applied Technology Council (ATC). (1992). Guidelines for cyclic seismic testing of components of steel structures.

24. FEMA-289 (1997). Connection Test Summaries, Reprot No. FEMA-289, Program to Reduce the Earthquake Hazards of Steel Moment Frame Structures, Federal Emergency Management Agency, Washington, June. 
692
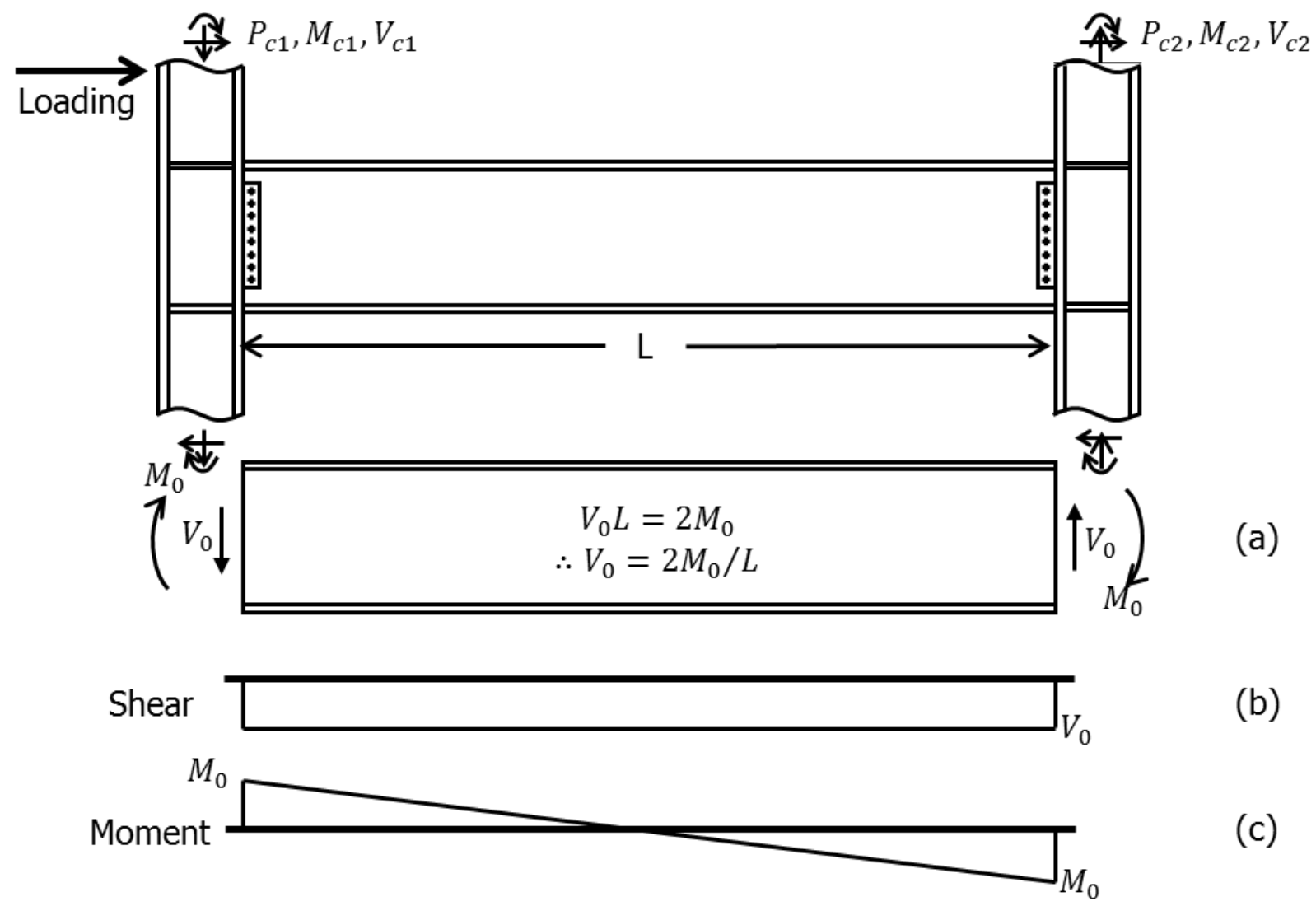

(b)

(c)

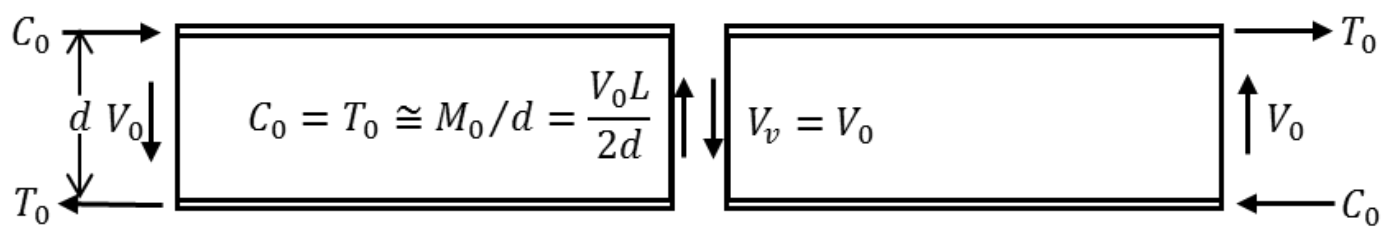

693

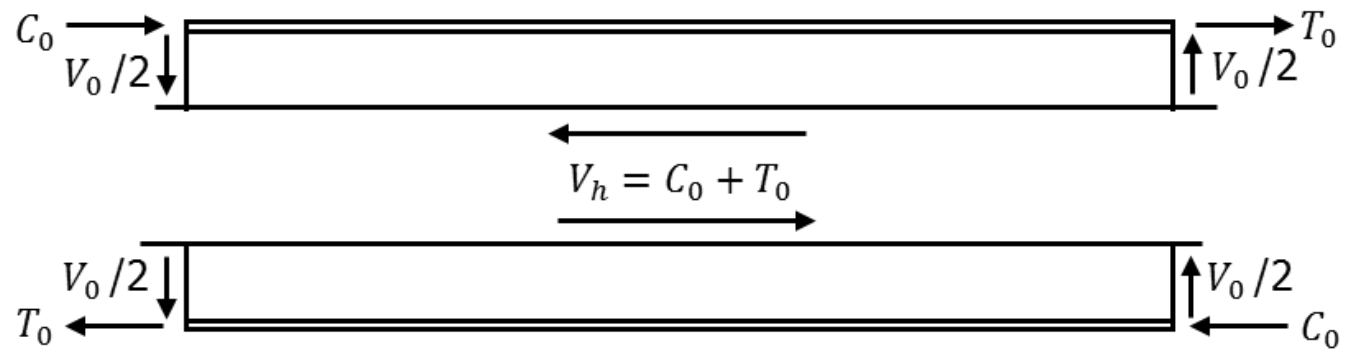

694 Figure 1 - Static equilibriums in a beam-column moment frame under lateral loading 695 


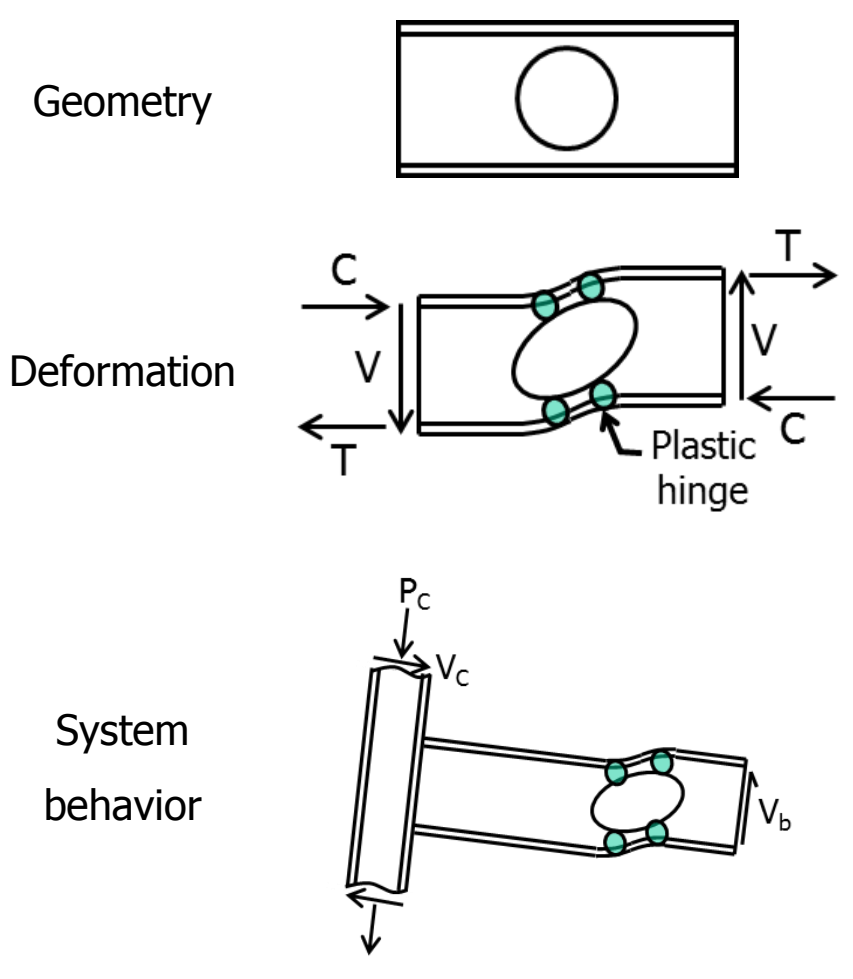

(a) Mode-A
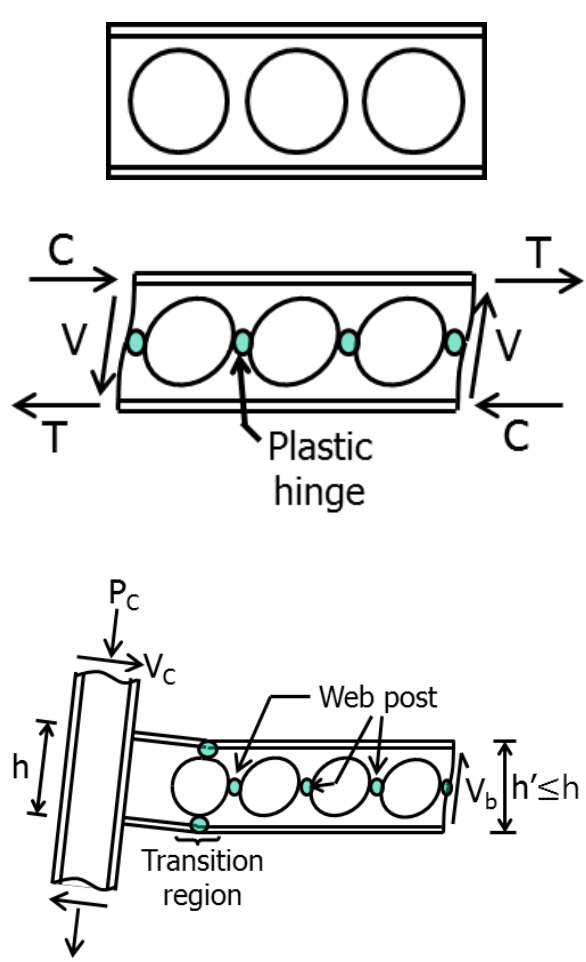

(b) Mode-B

697 Figure 2 - Inelastic mechanisms and deformations of reduced web-section beams (h' = height of 698 deformed beam, $\mathrm{h}=$ height of original beam)

699 


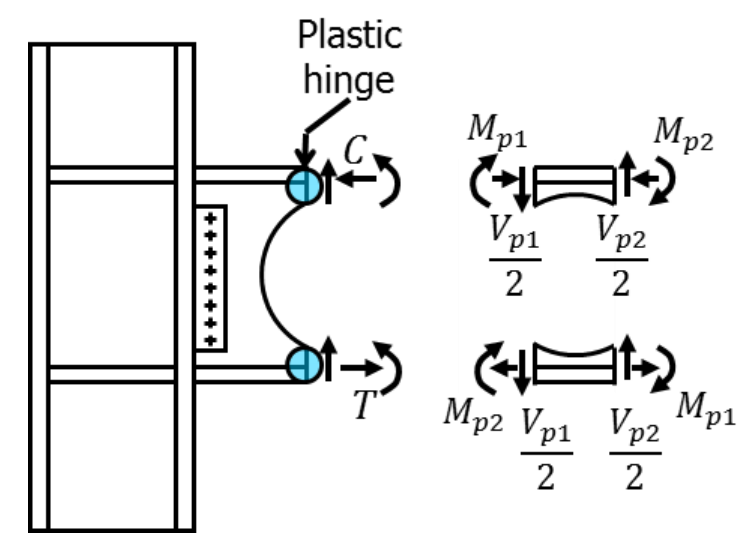

(a) Mode-A

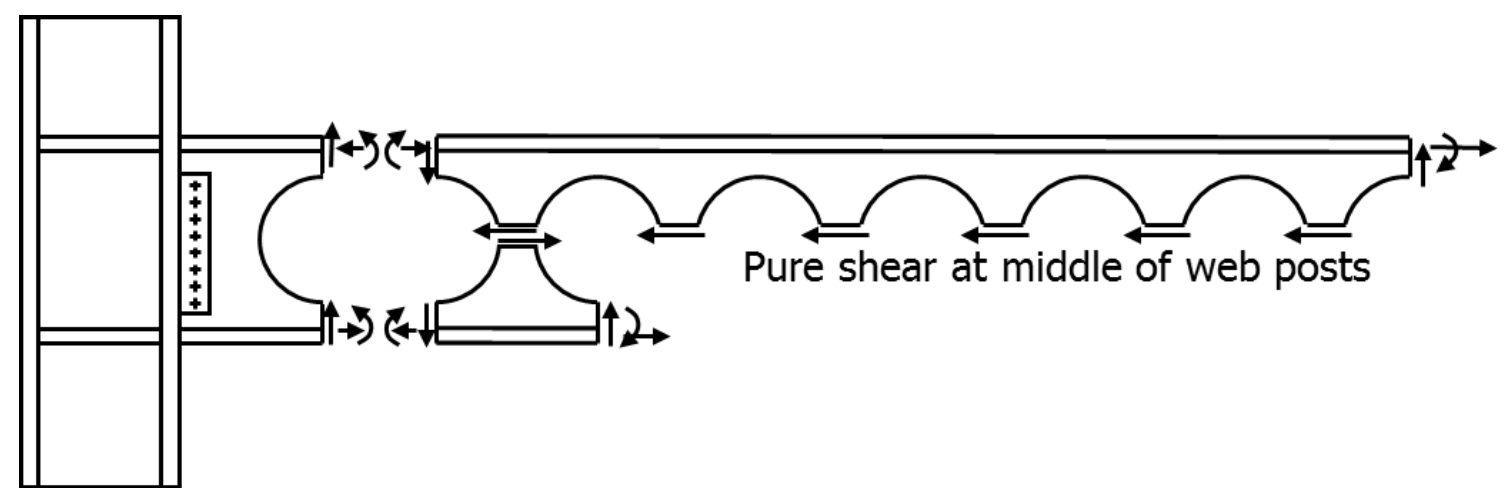

(b) Mode-B

701 Figure 3 - Free-body diagrams for reduced web-section beams in two inelastic mechanisms 702 703

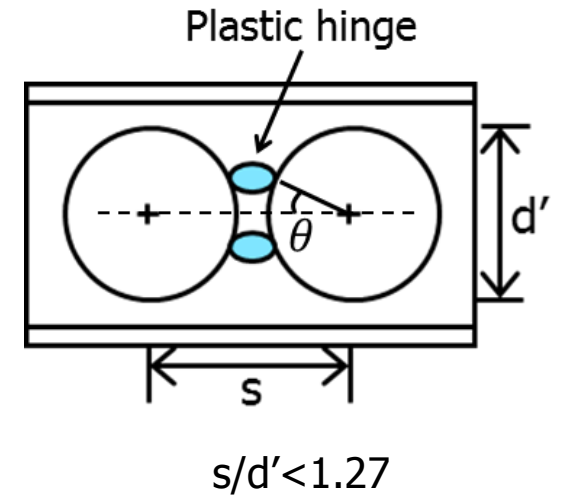

(a) Flexural hinging

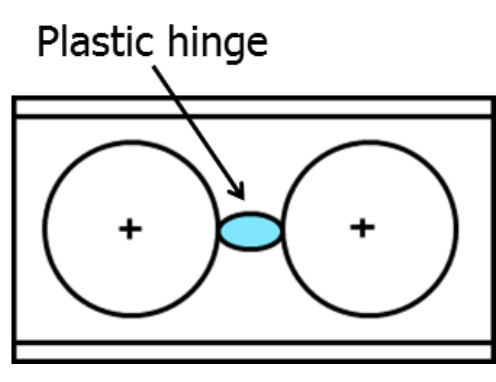

$\mathrm{s} / \mathrm{d}^{\prime}>1.27$

(b) Shear yielding

704 Figure 4 - Yielding modes of web posts 


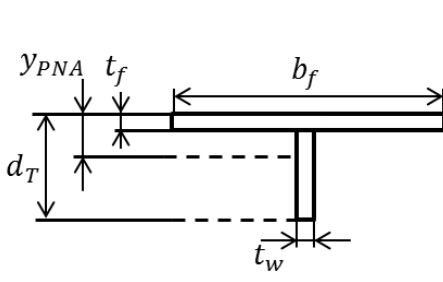

Section A-A

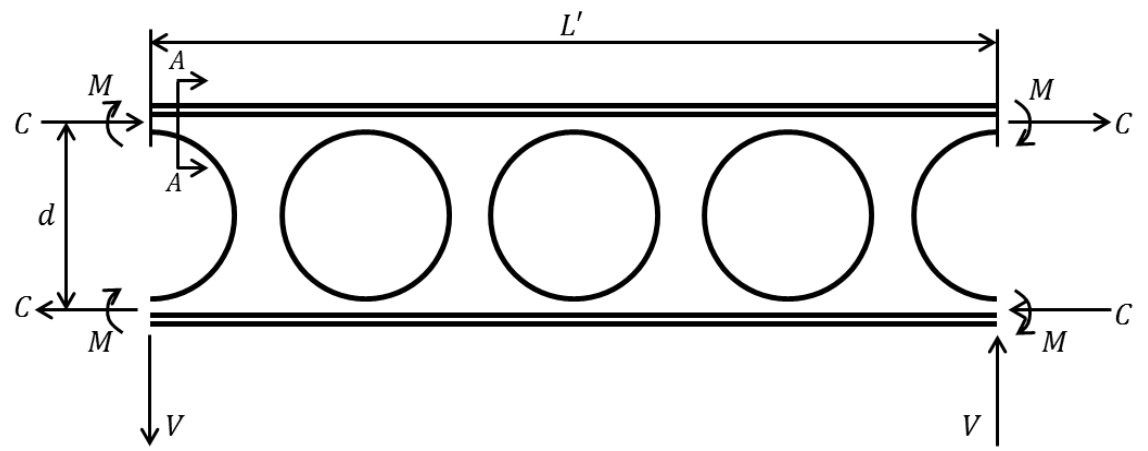

708

(a)

(b)

709 Figure 5 - Strength determination of RWS beams governed by Mode-B mechanism: (a) notation, and (b) free-body diagram for overall equilibrium (forces are shown in their absolute sense).

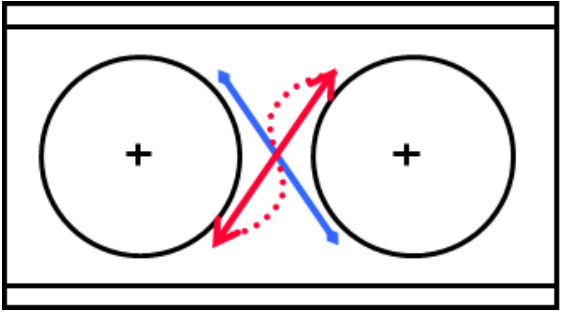

\section{Compression strut} Tension tie

714 Figure 6 - A strut and tie idealization for force transmission through a web post. The dotted line 715 indicates out-of-plane buckling.

716 


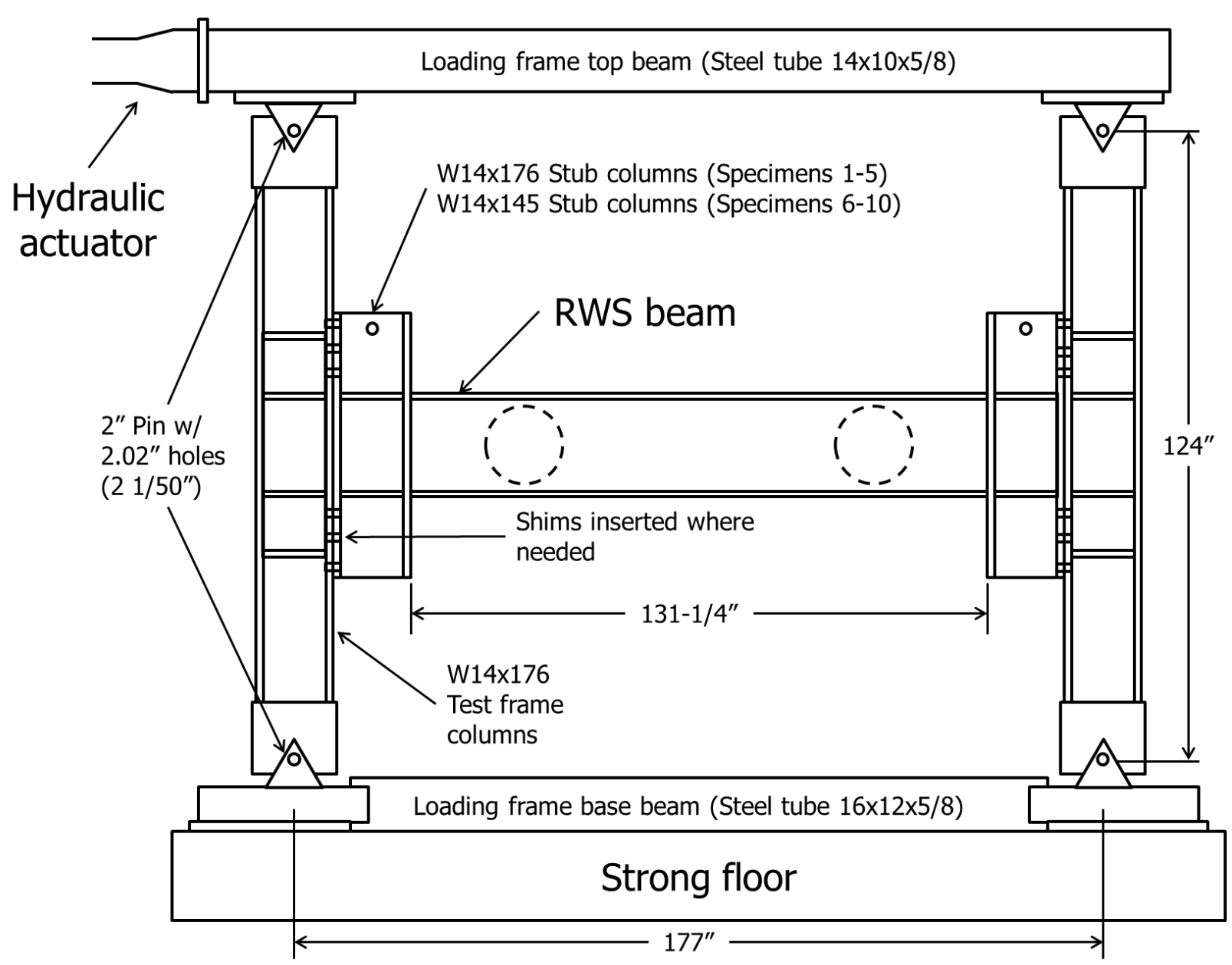

719 Figure 7 - Test setup and overall specimen dimensions $(1$ inch $=25.4 \mathrm{~mm})$ 


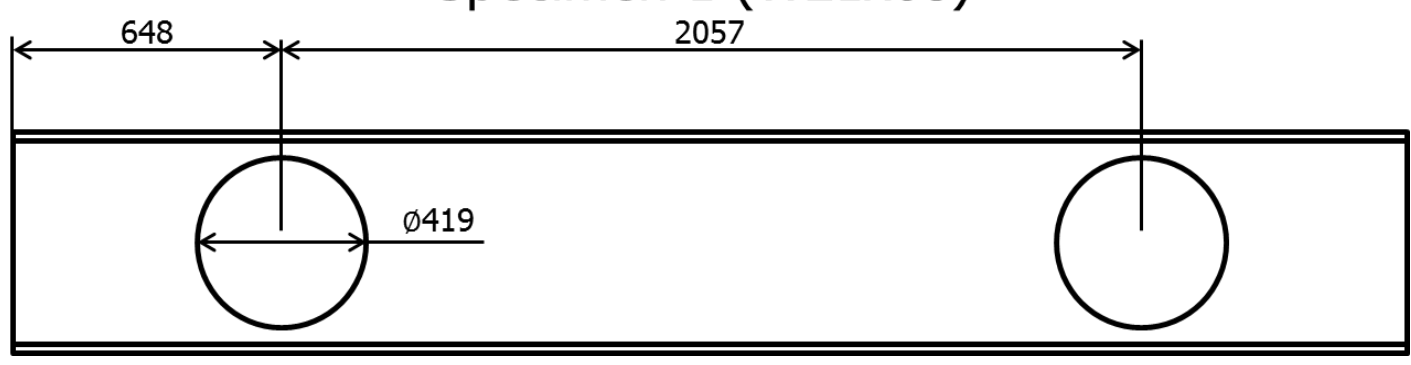

Specimen 2 (W21x68)

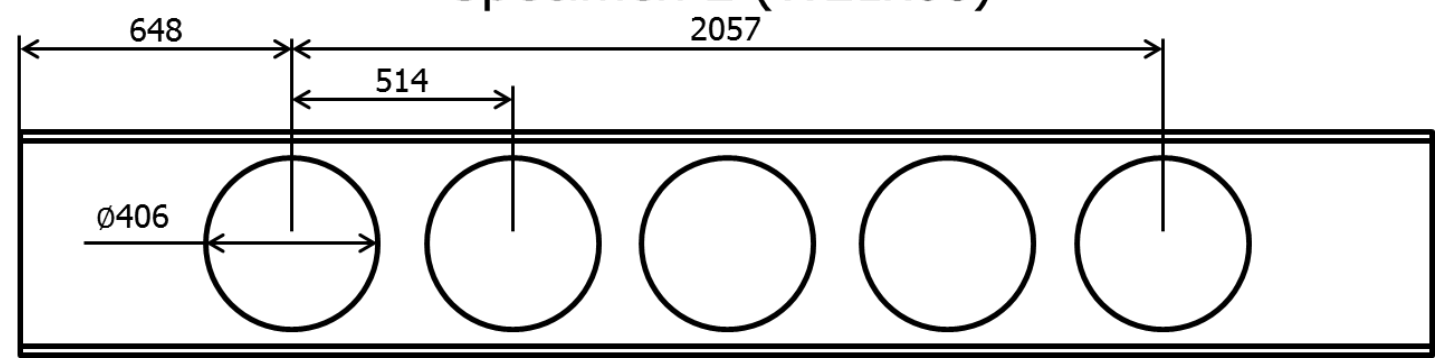

Specimen 3 (W21x68)

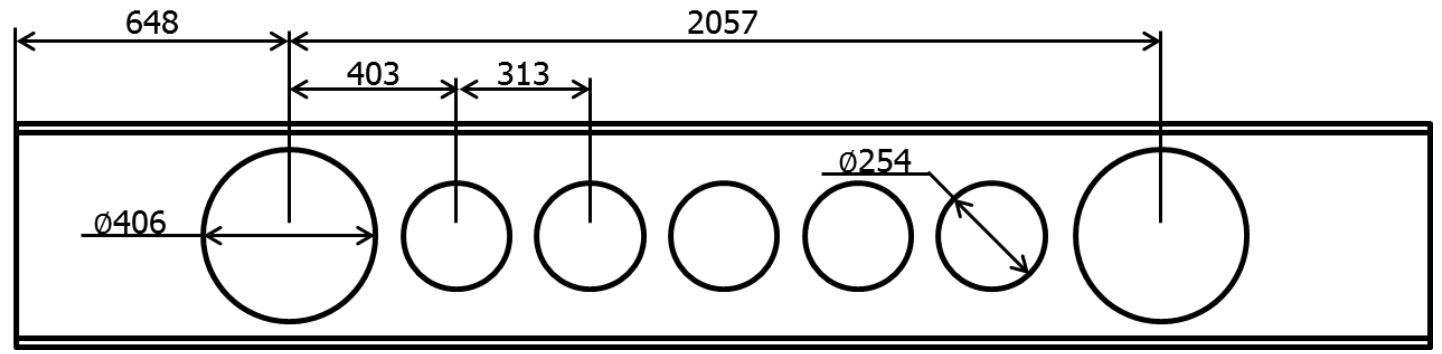

Specimen 4 (W21x68)

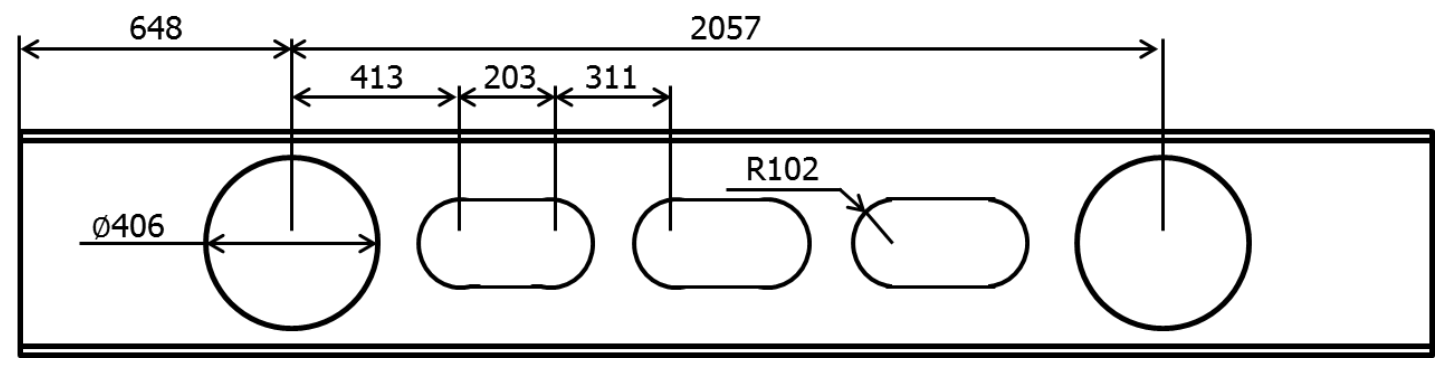

Specimen 5 (W21x68)

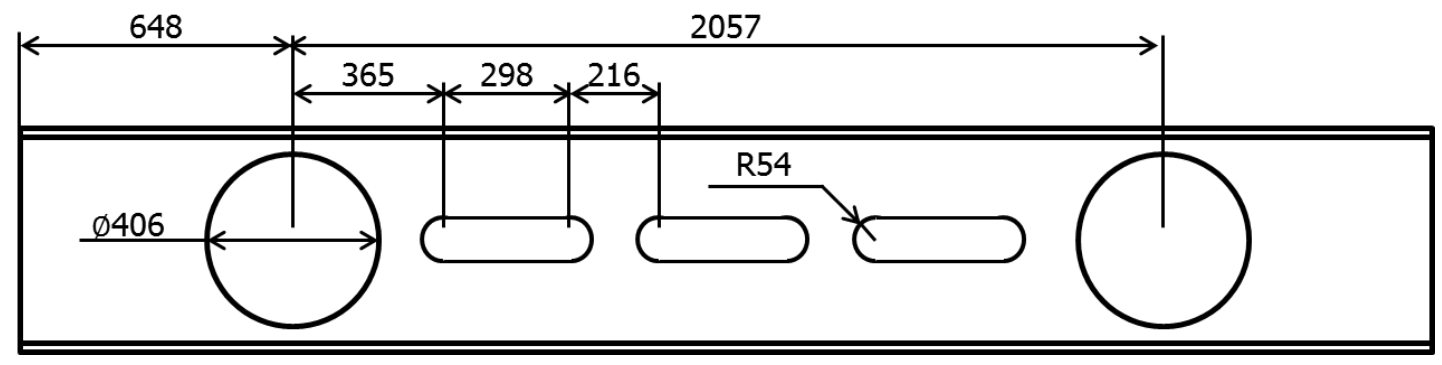

727 Figure 8 - Web opening geometries in Phase 1 specimens (units: mm) 


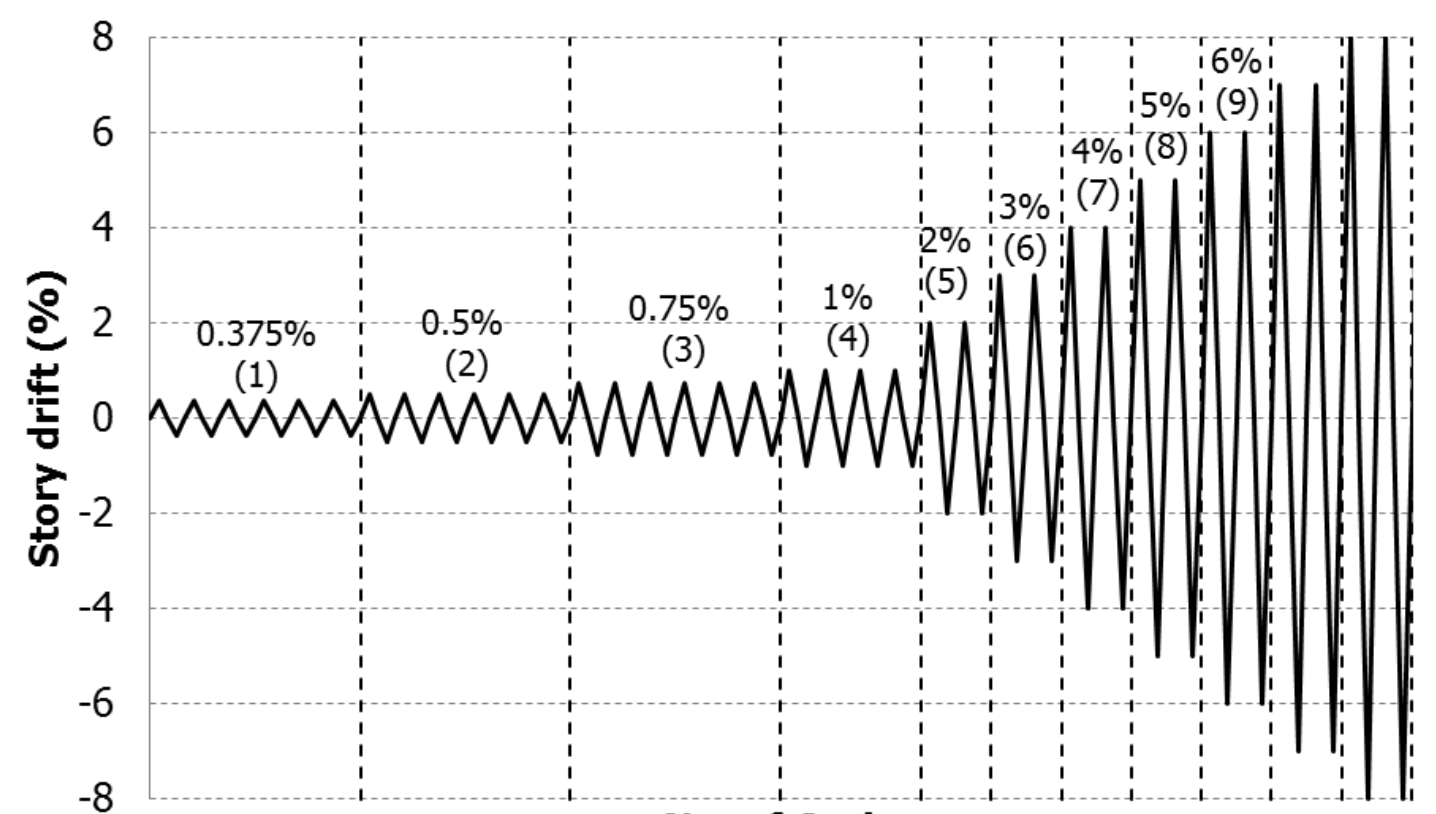

No. of Cycle

729

730 Figure 9 - Loading history ("Cycle numbers" in parentheses are used to present strain gage data 731 in Figure 16 to Figure 18)

732

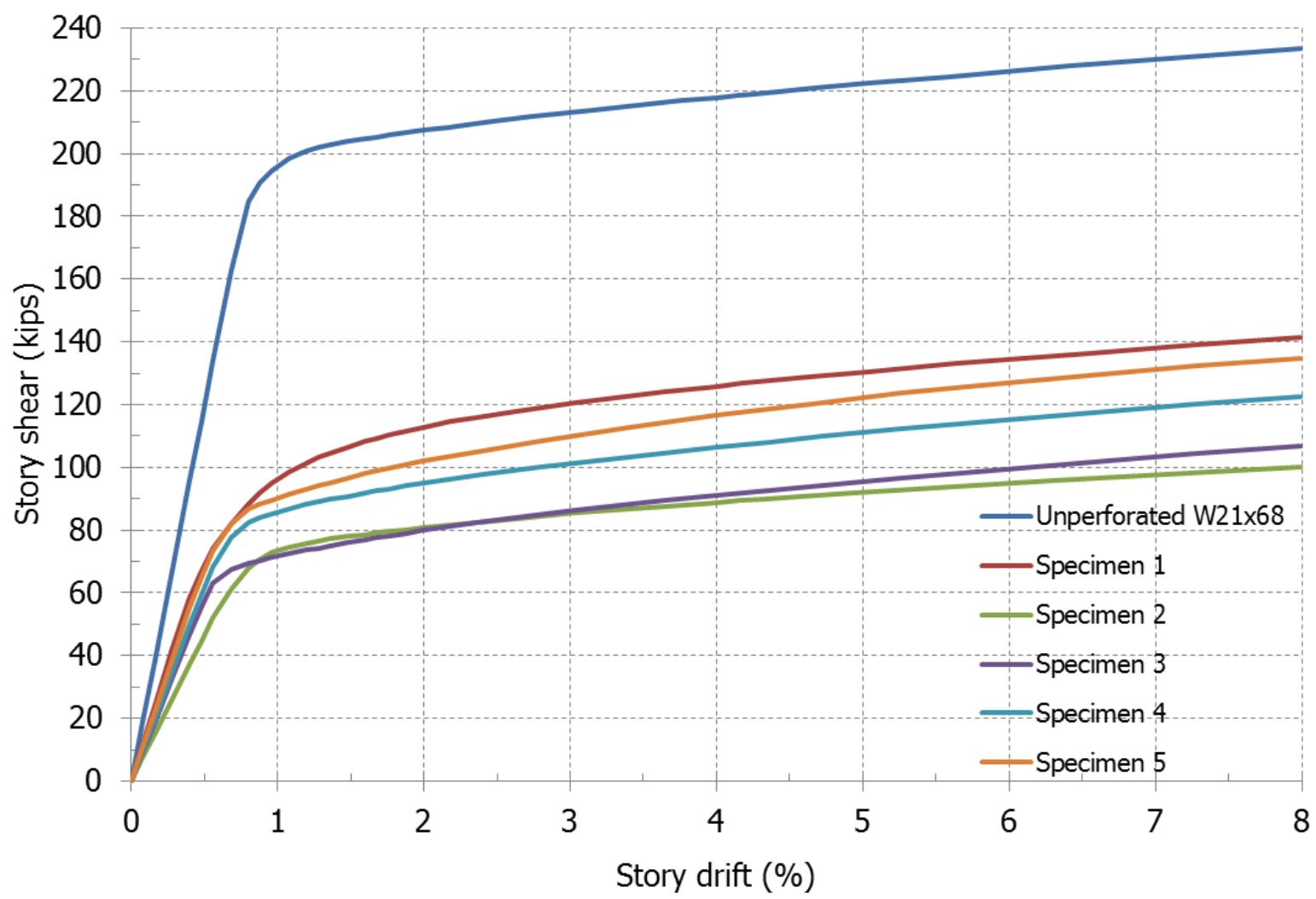

734 Figure 10 - Nonlinear finite element analysis results for Phase 1 specimens $(1 \mathrm{kip}=4.45 \mathrm{kN})$ 


\section{Specimen 1}

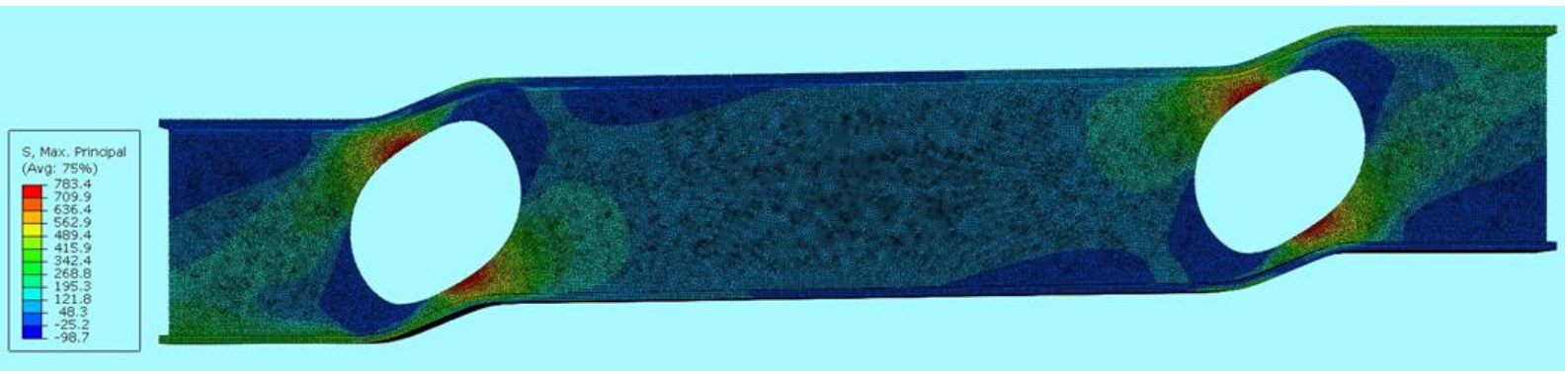

Specimen 2

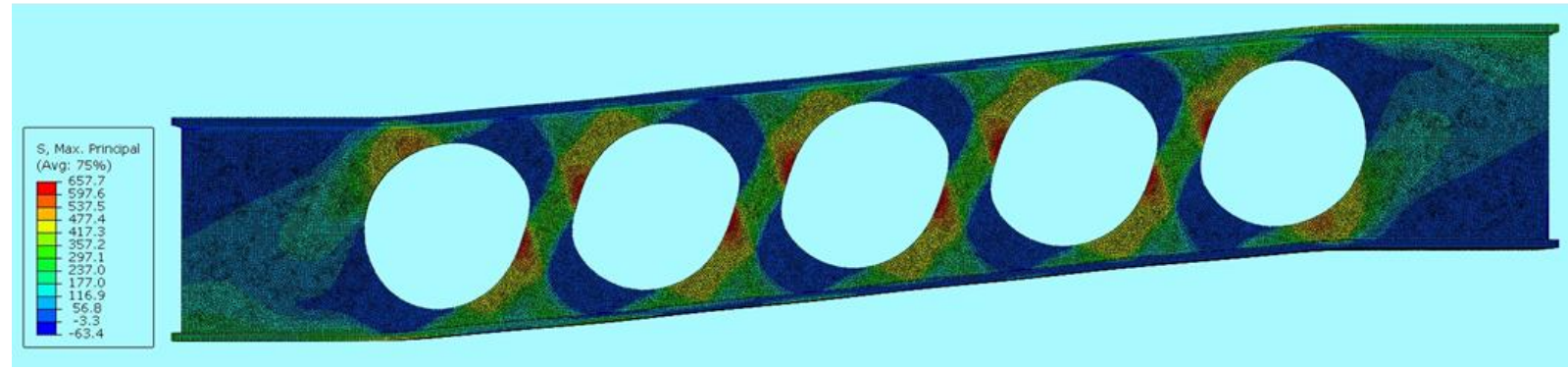

Specimen 3

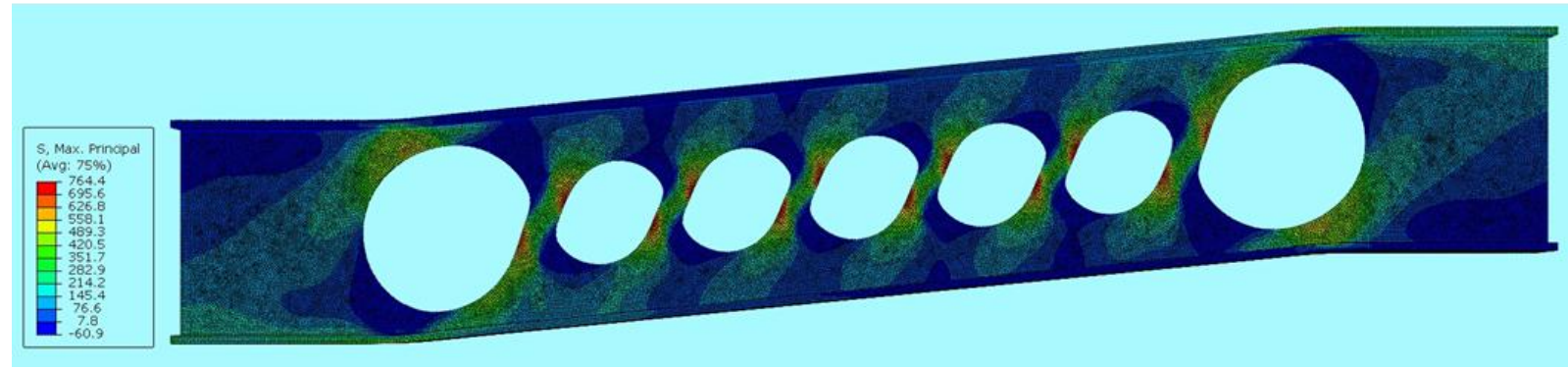

Specimen 4

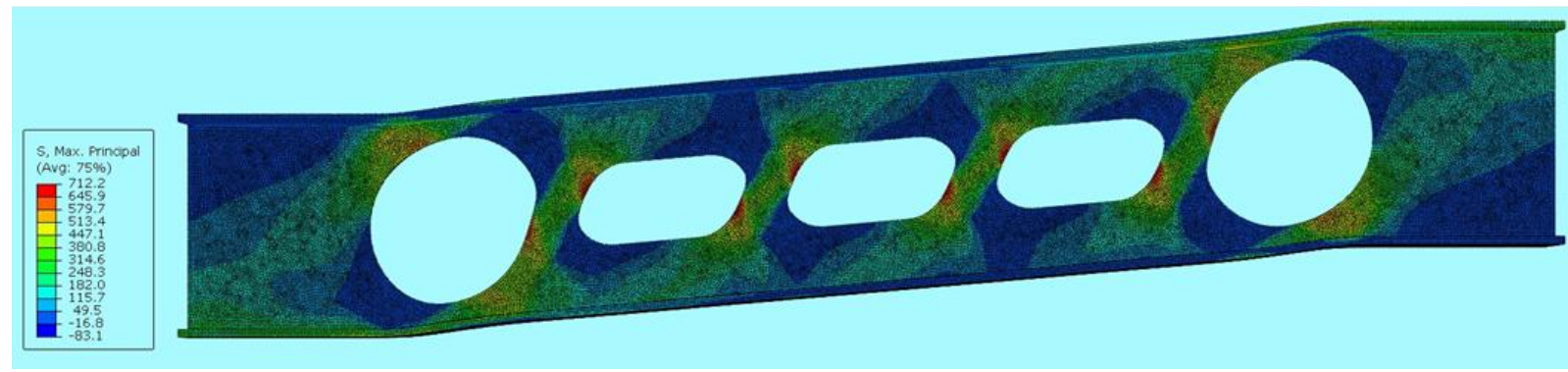

\section{Specimen 5}

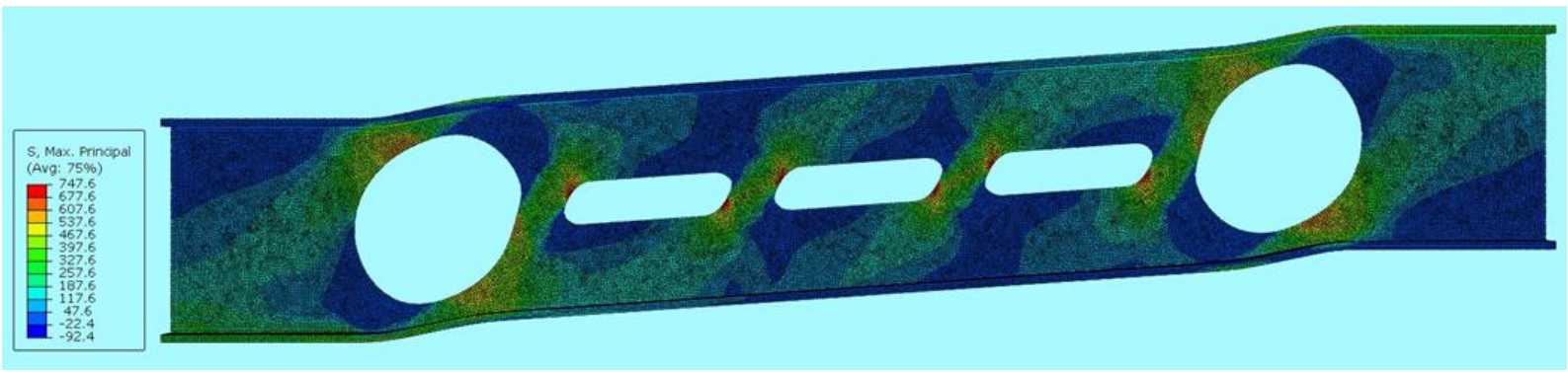

Figure $11-$ Deformed shape $($ amplifier $=1.5)$ and maximum principal stress distribution at $5 \%$

742 beam chord rotation (units: $\mathrm{MPa}$ ) 
Specimen 2

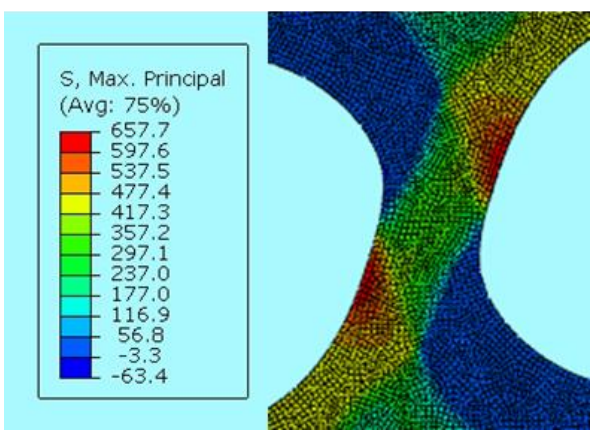

Specimen 4

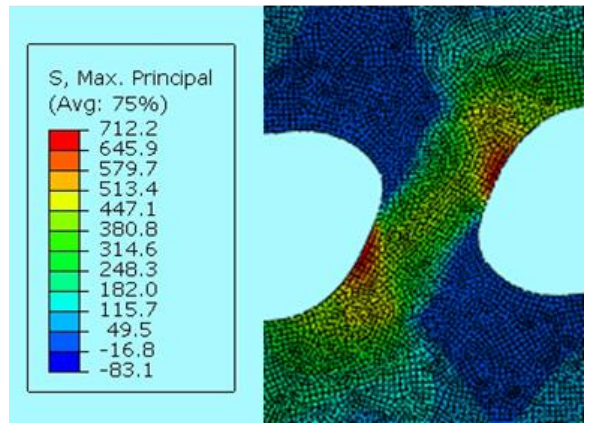

Specimen 3

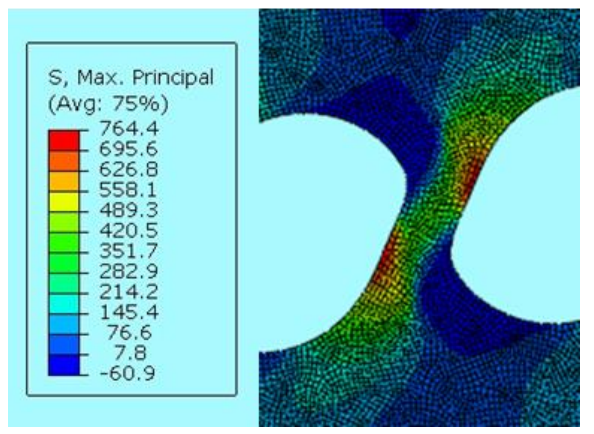

Specimen 5

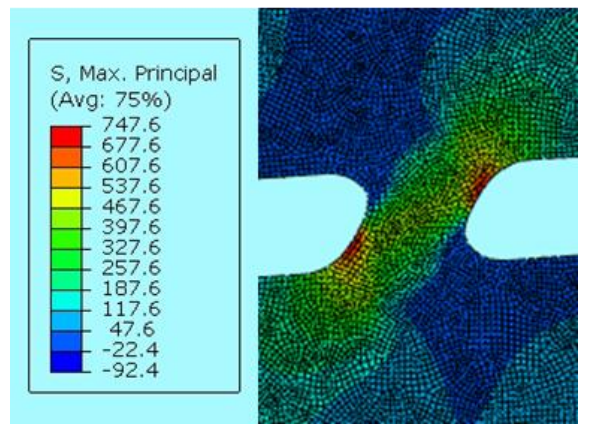

744

745 Figure 12 - Deformed shapes of web posts in Specimens 2 to 5 from nonlinear finite element

746 analysis (amplifier $=1.5$ ); the maximum principal stress is plotted at $5 \%$ beam chord rotation

747 (units: MPa) 


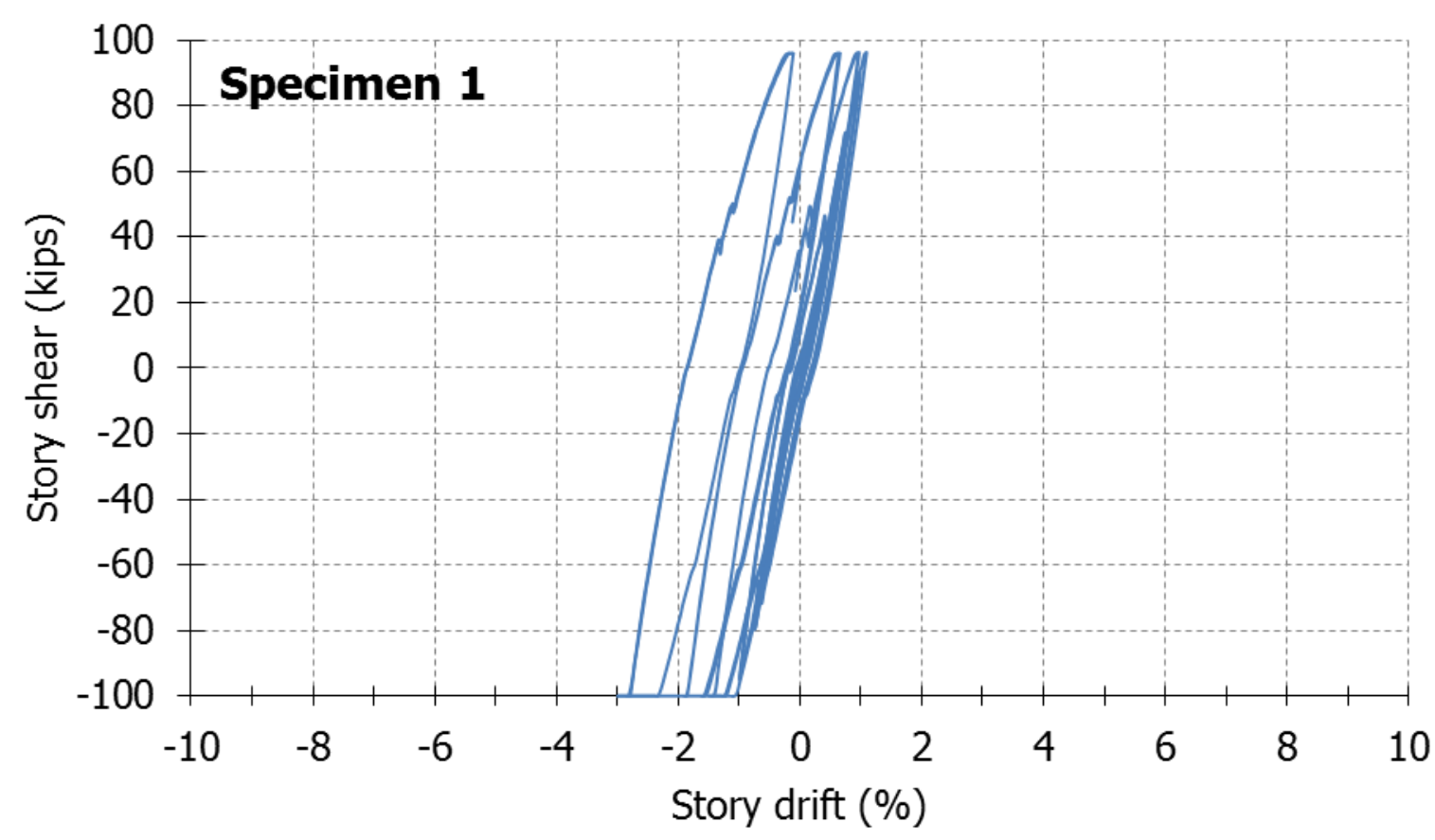

750

751

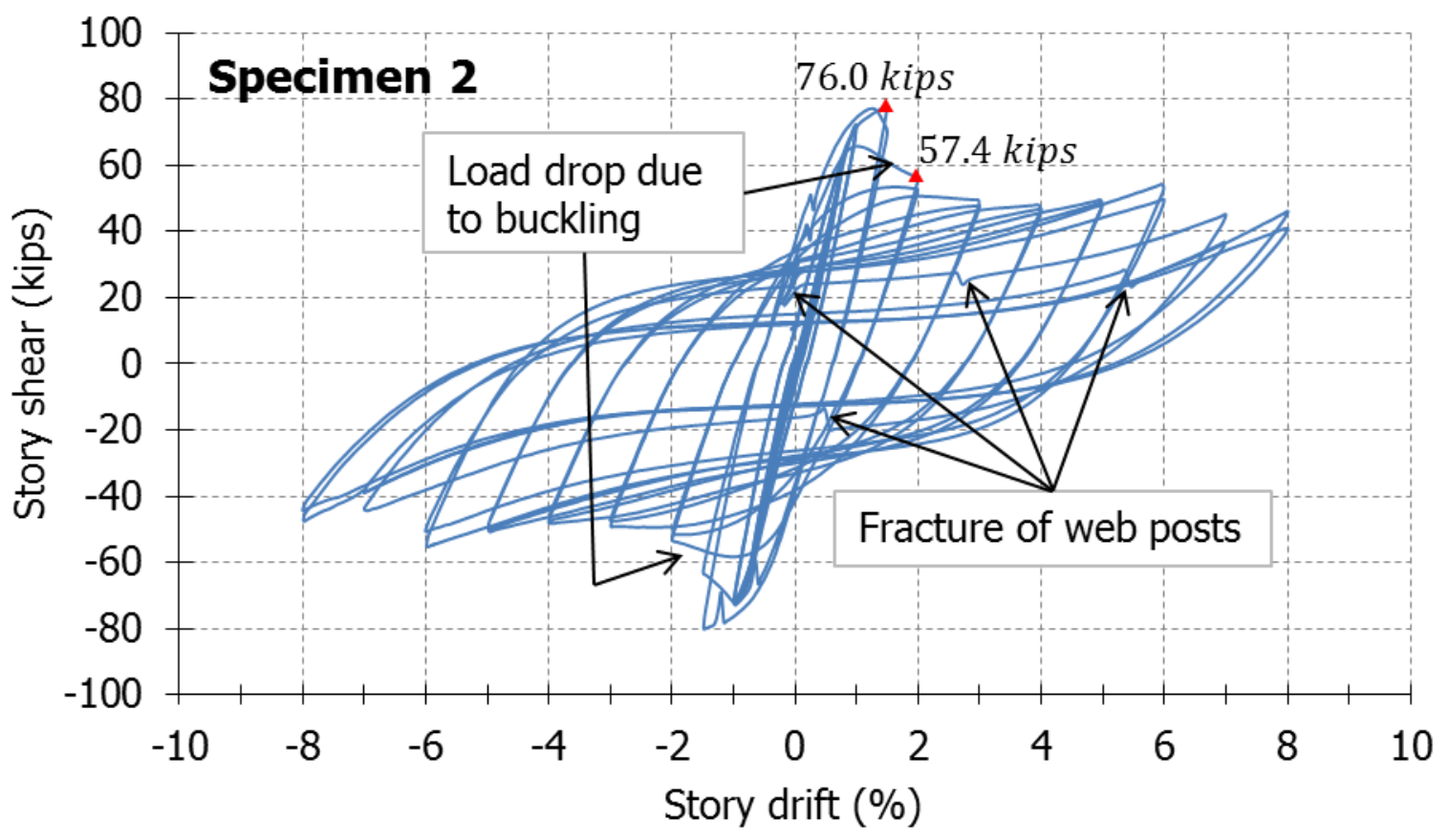

752 


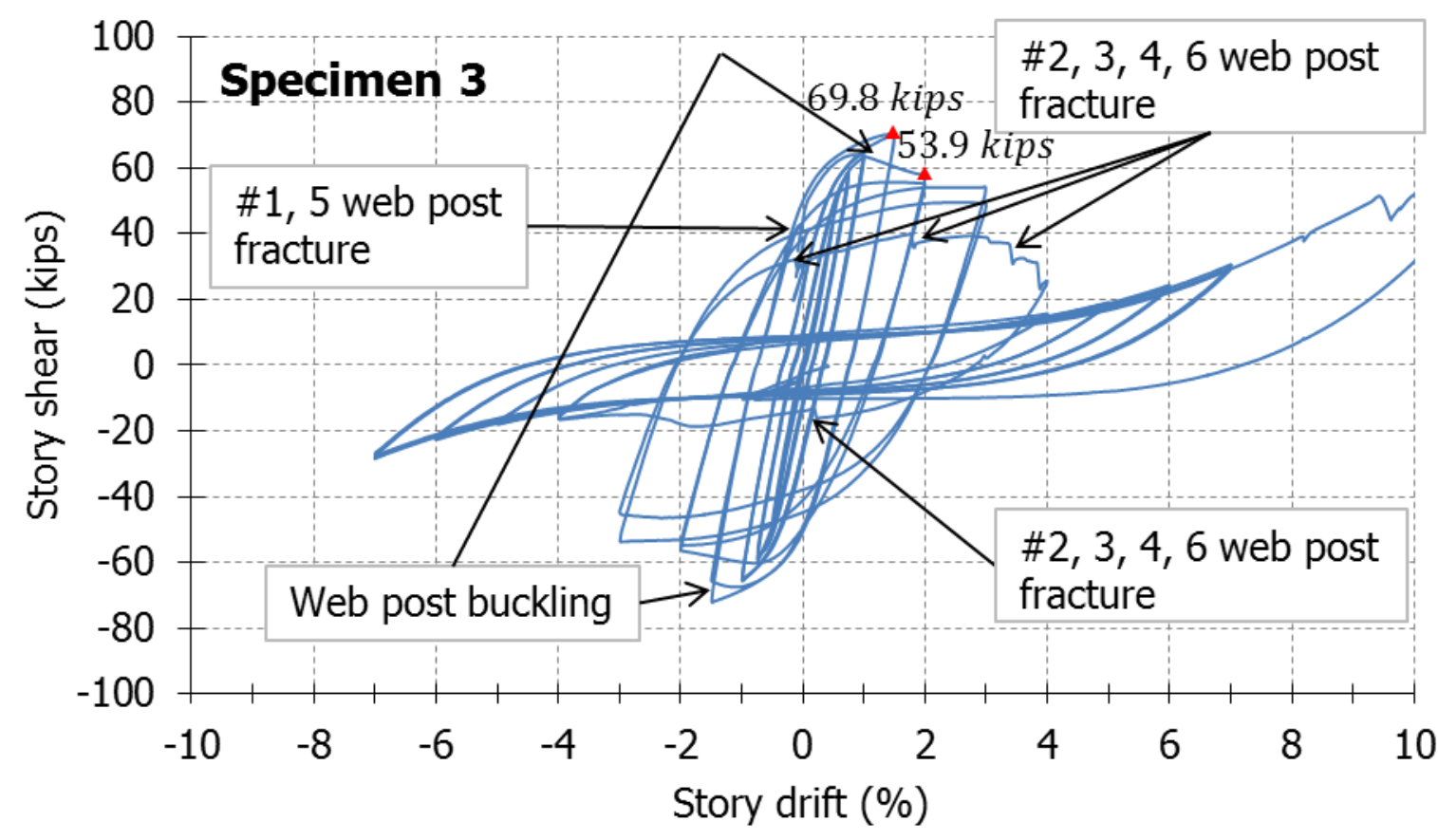

754

755

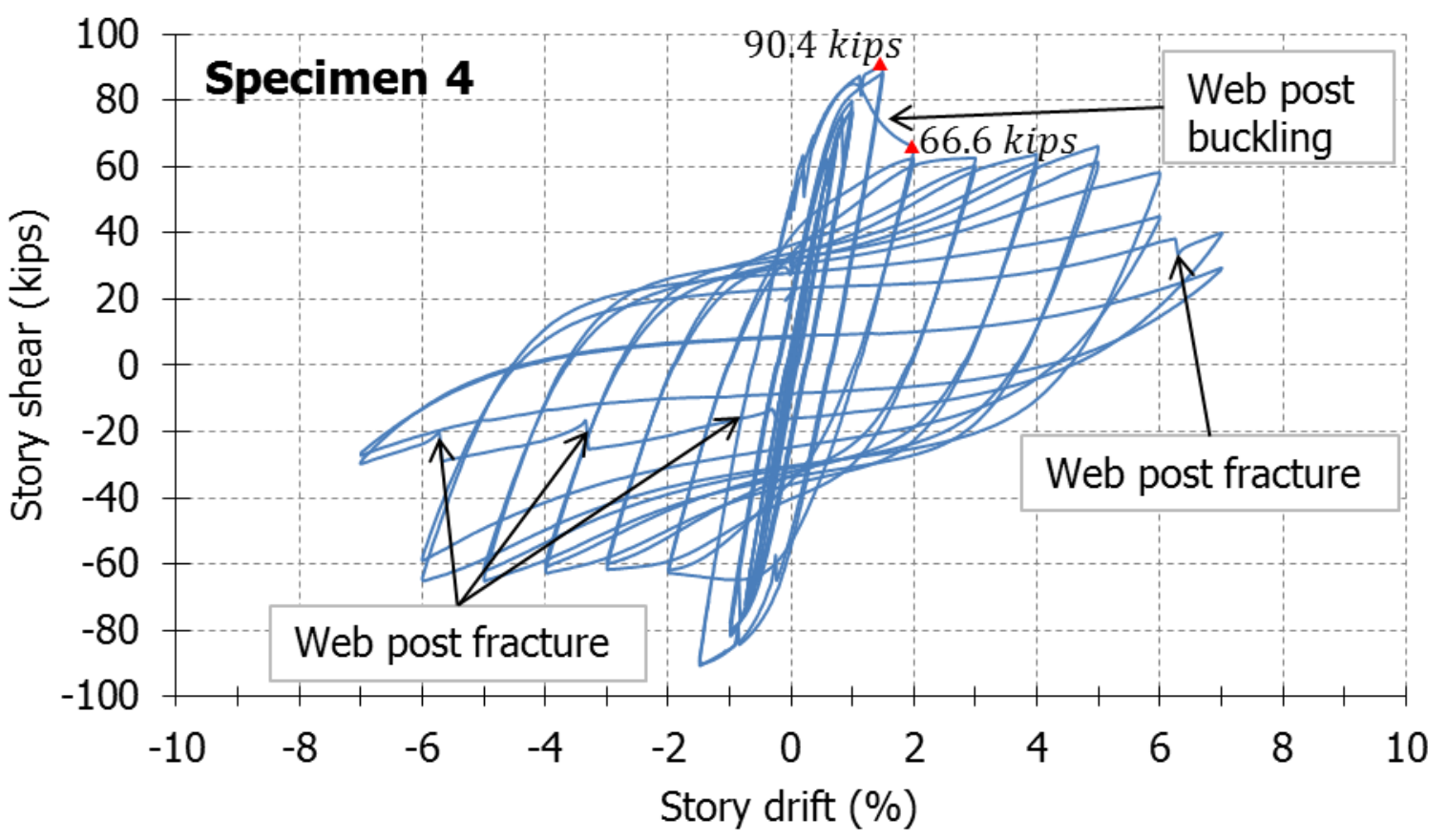

756 


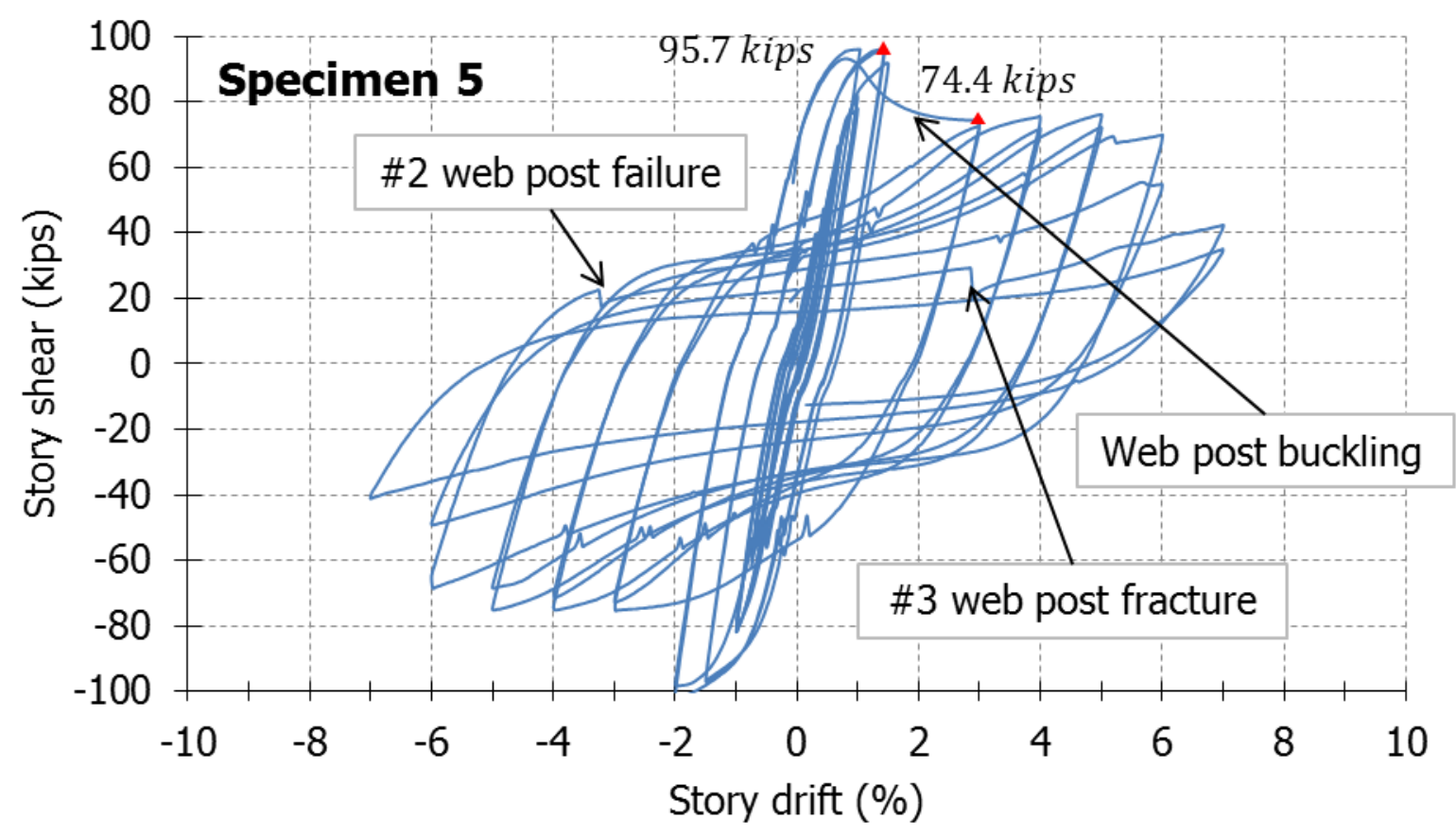

758

759

760

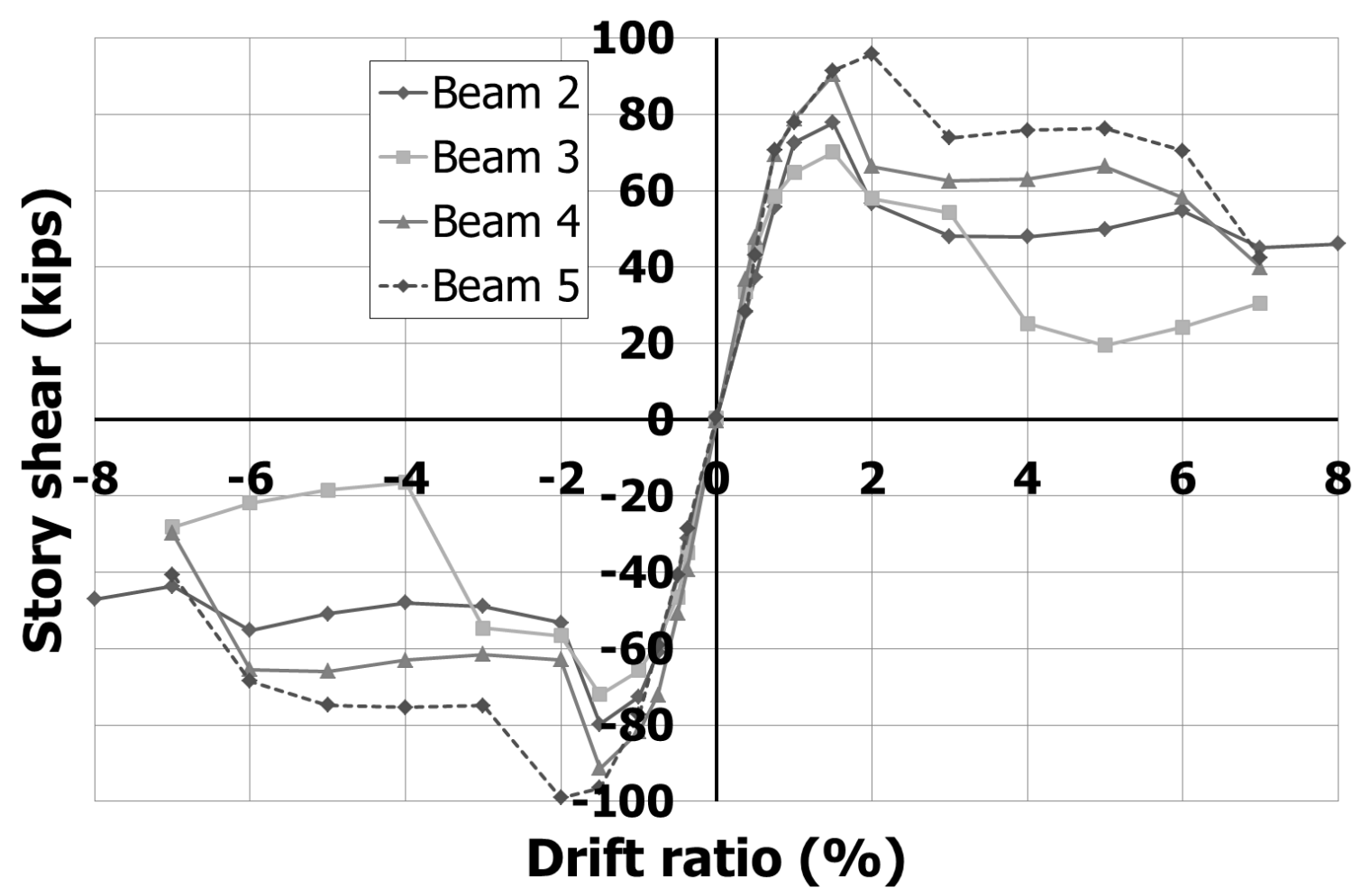

761 Figure 13 - Story shear-story drift responses in Phase 1 specimens ( 1 kip $=4.45 \mathrm{kN})$

762 
Specimen 1

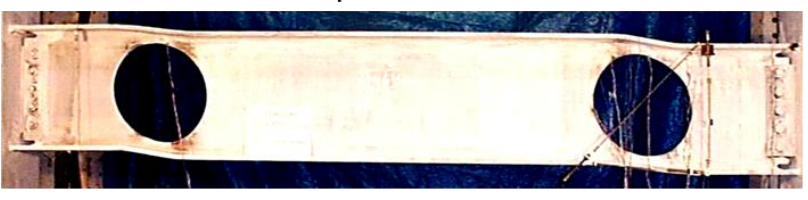

Specimen 3

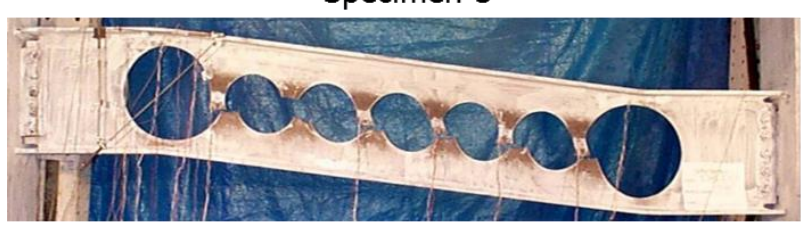

Specimen 2

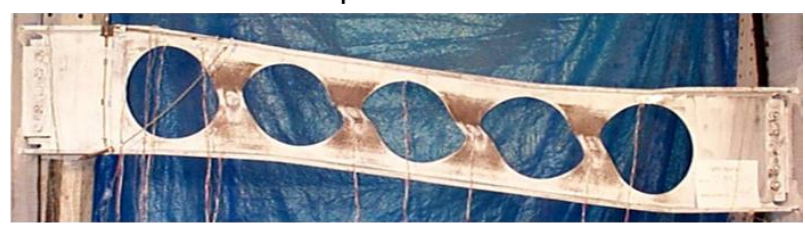

Specimen 4

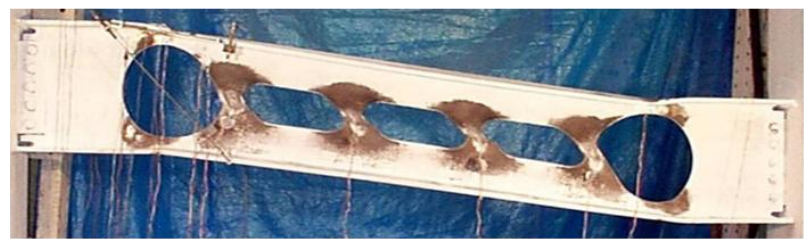

Specimen 5

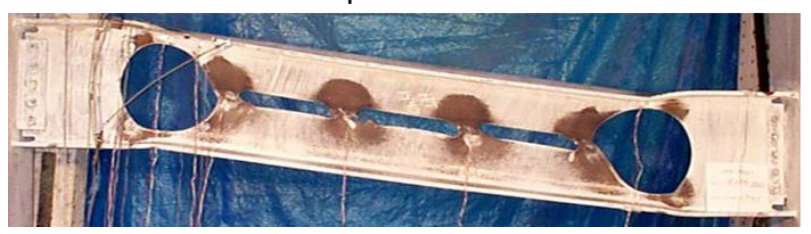

Figure 14 - Deformed shapes of Phase 1 specimens near the end of testing

766

767

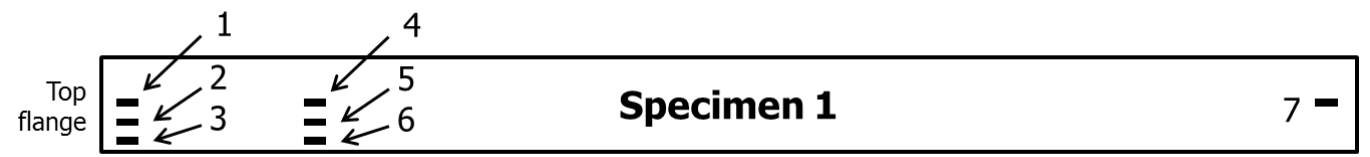

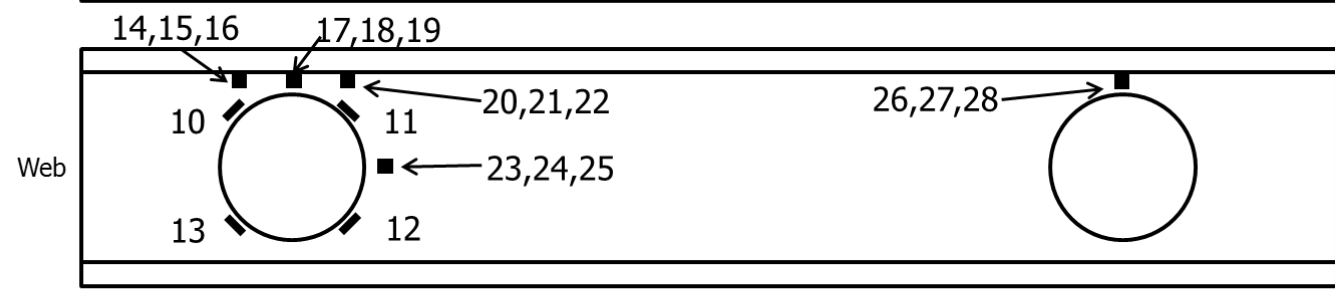

768

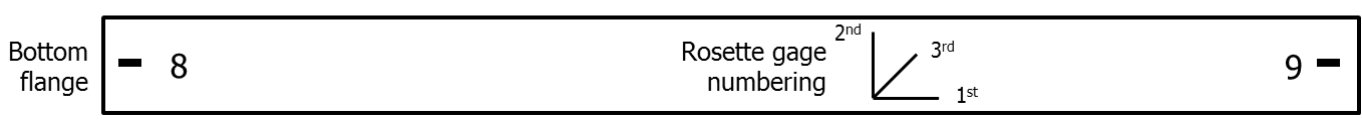

769

\section{Specimen 2}

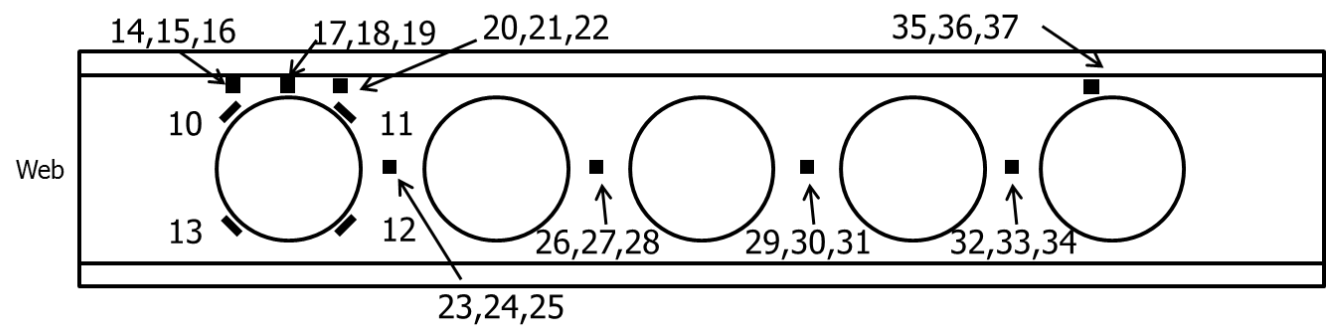




\section{Specimen 3}

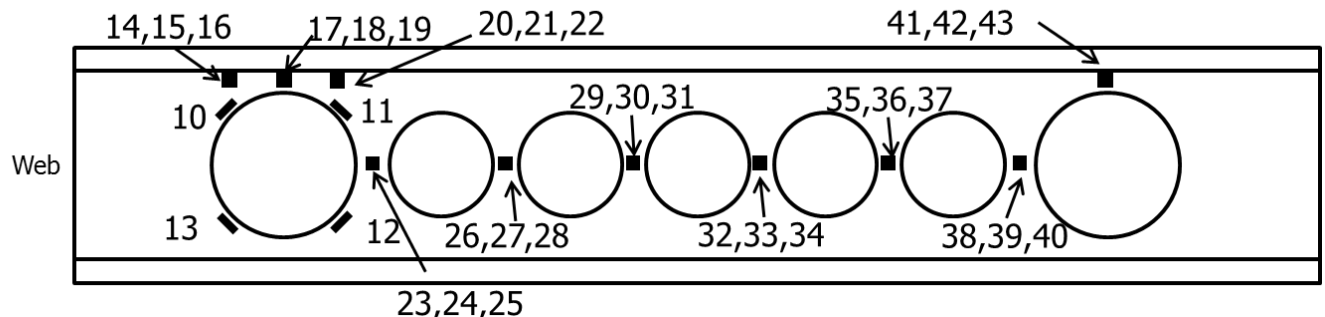

771

\section{Specimen 4}

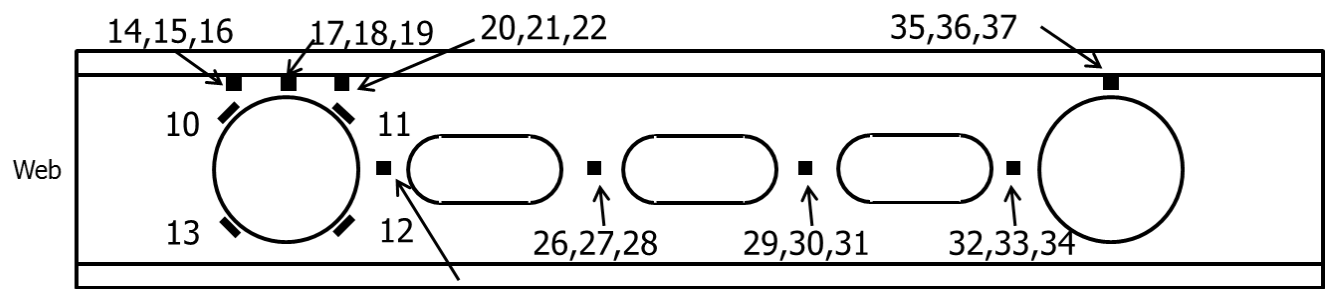

772

\section{Specimen 5}

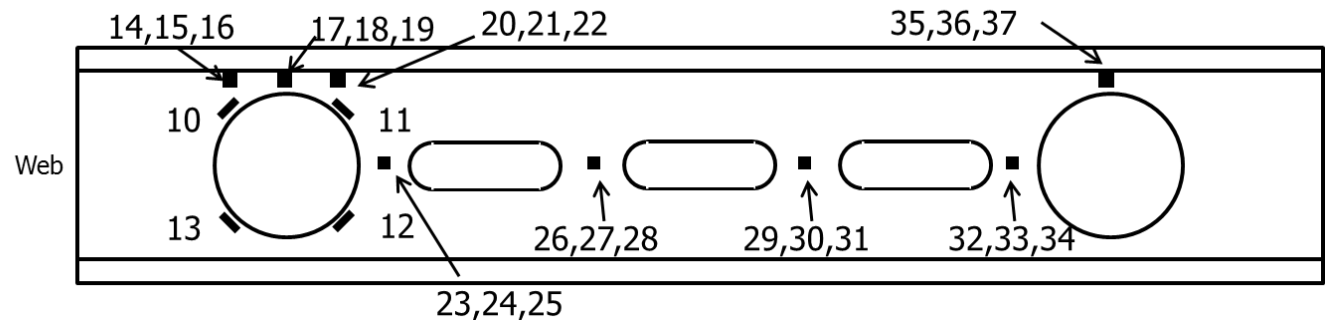

773

774 Figure 15 - Locations of electrical resistance strain gauges (note: gages on top and bottom 775 flanges are identical in all specimens)

776

777 


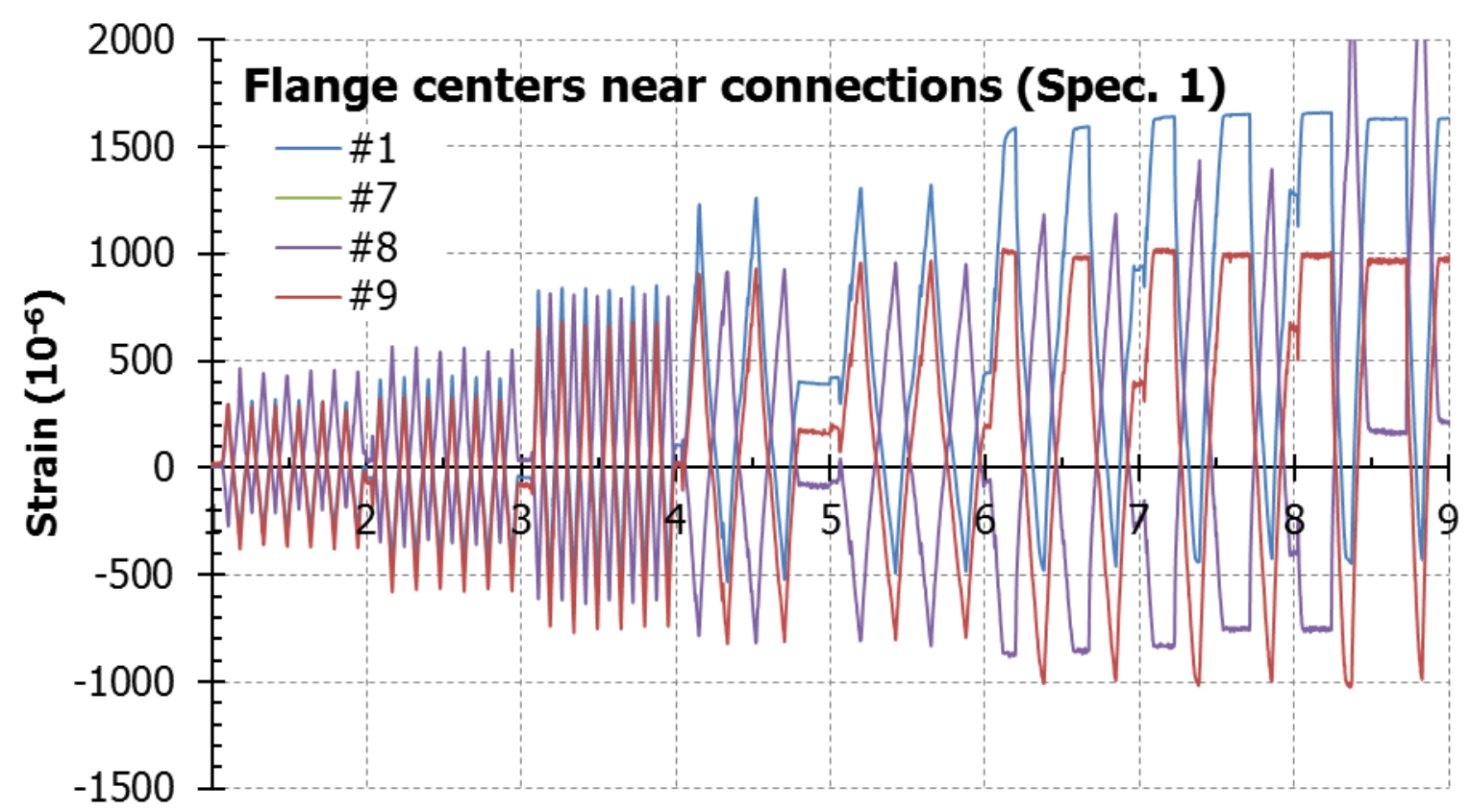

778

Cycle number

779

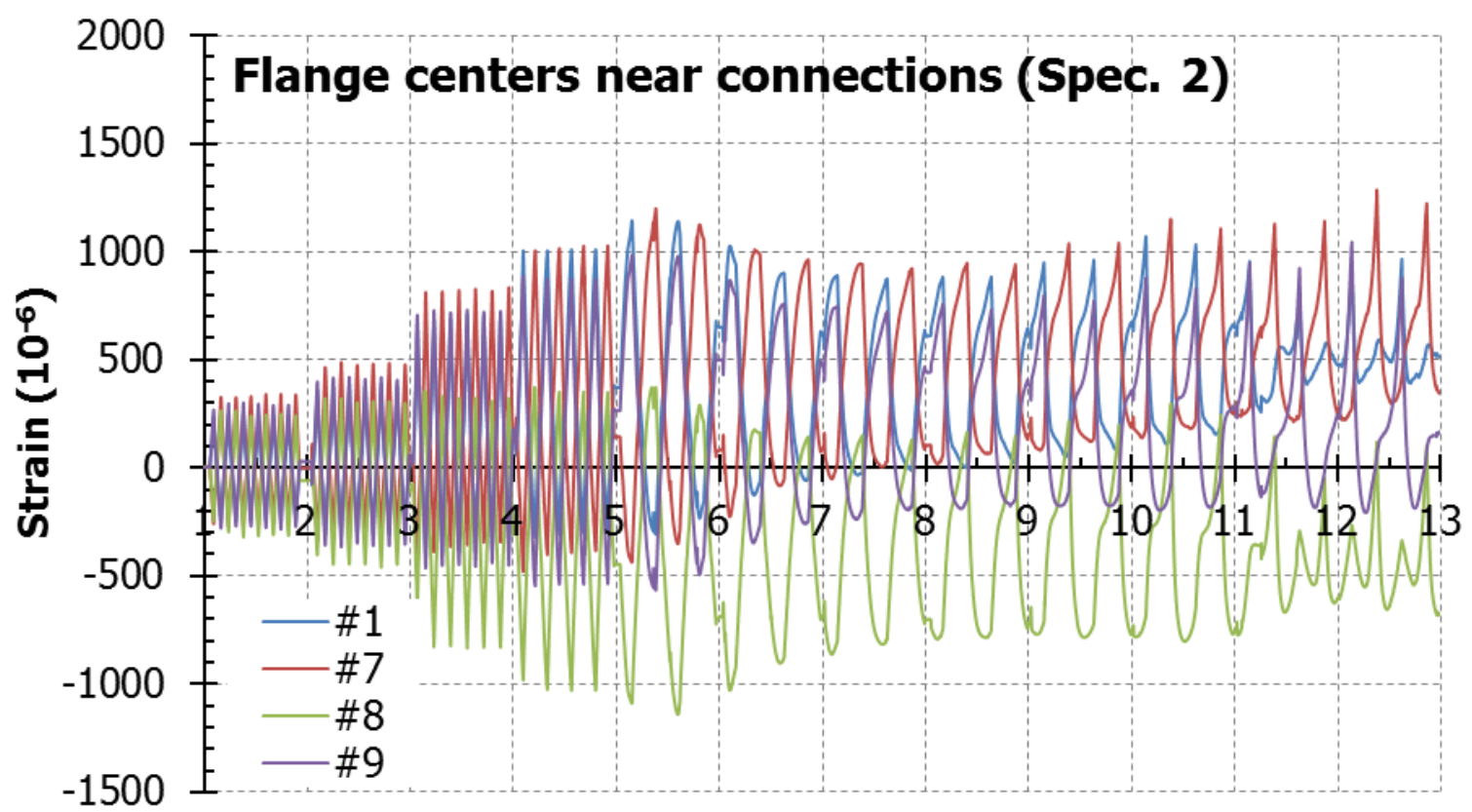

780

Cycle number

781

782 


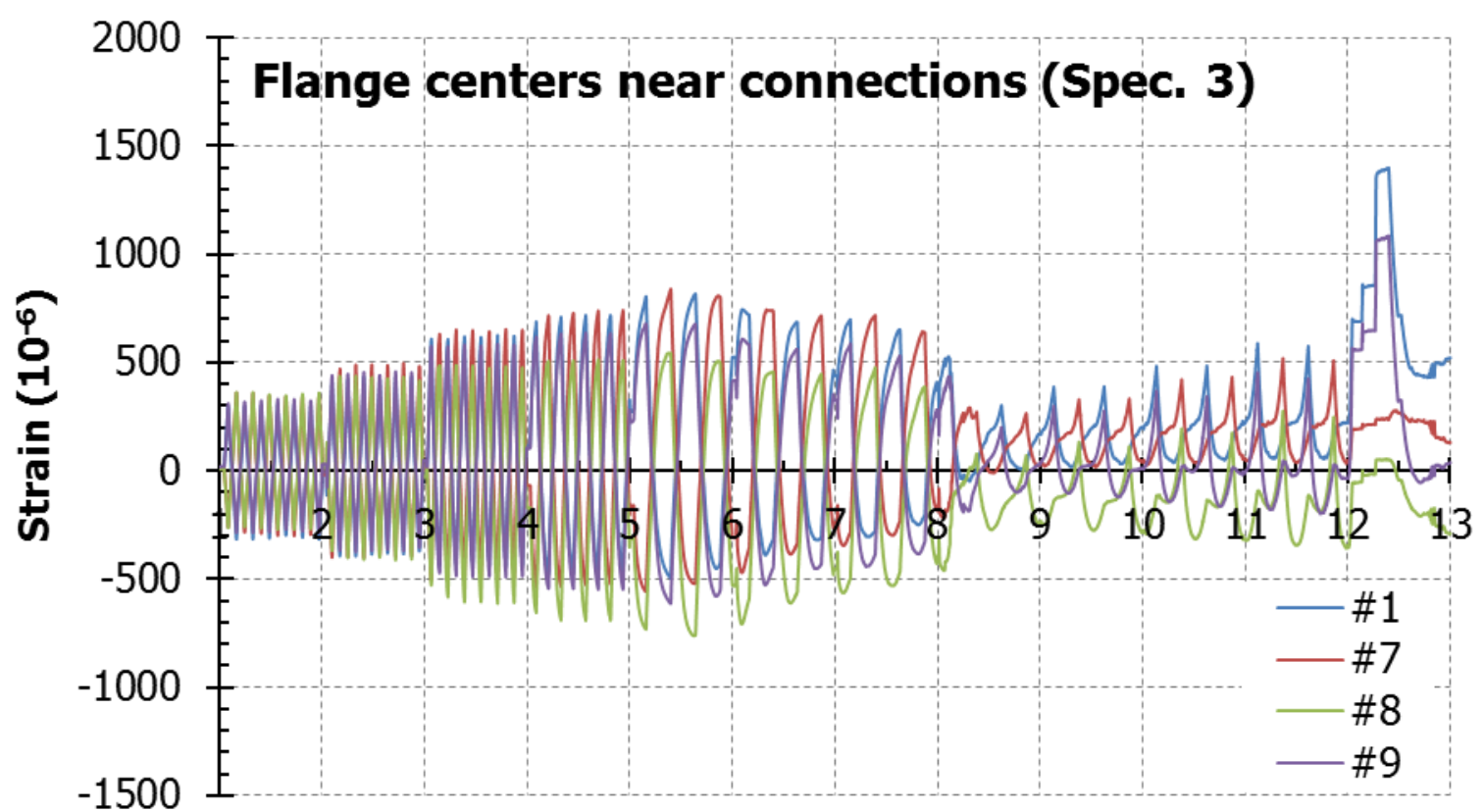

783

Cycle number

784

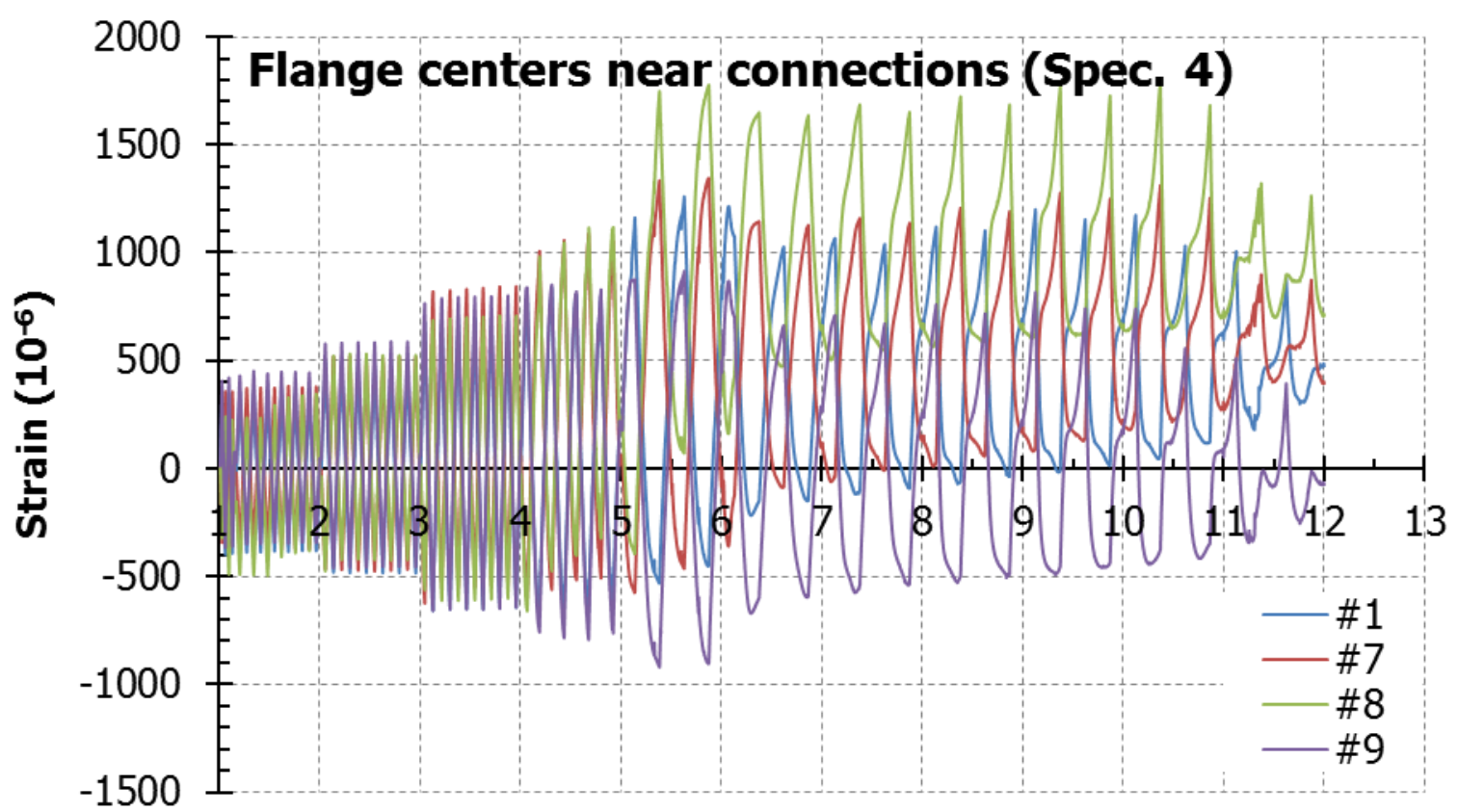

Cycle number

785

786 


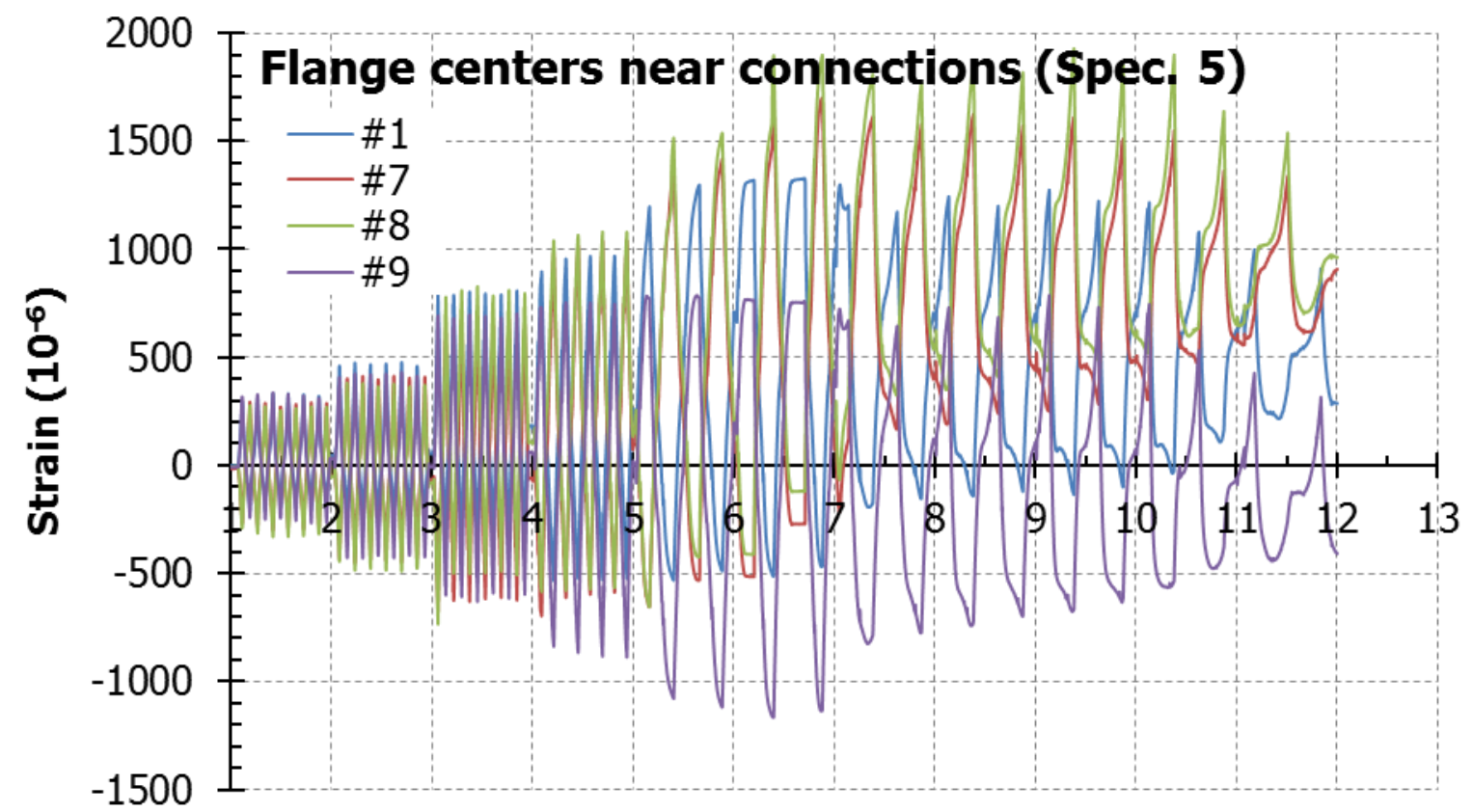

789 Figure 16 - Strains at the top and bottom flanges near the connections (each cycle number stands for a story drift level, as noted in Figure 9)

791

792

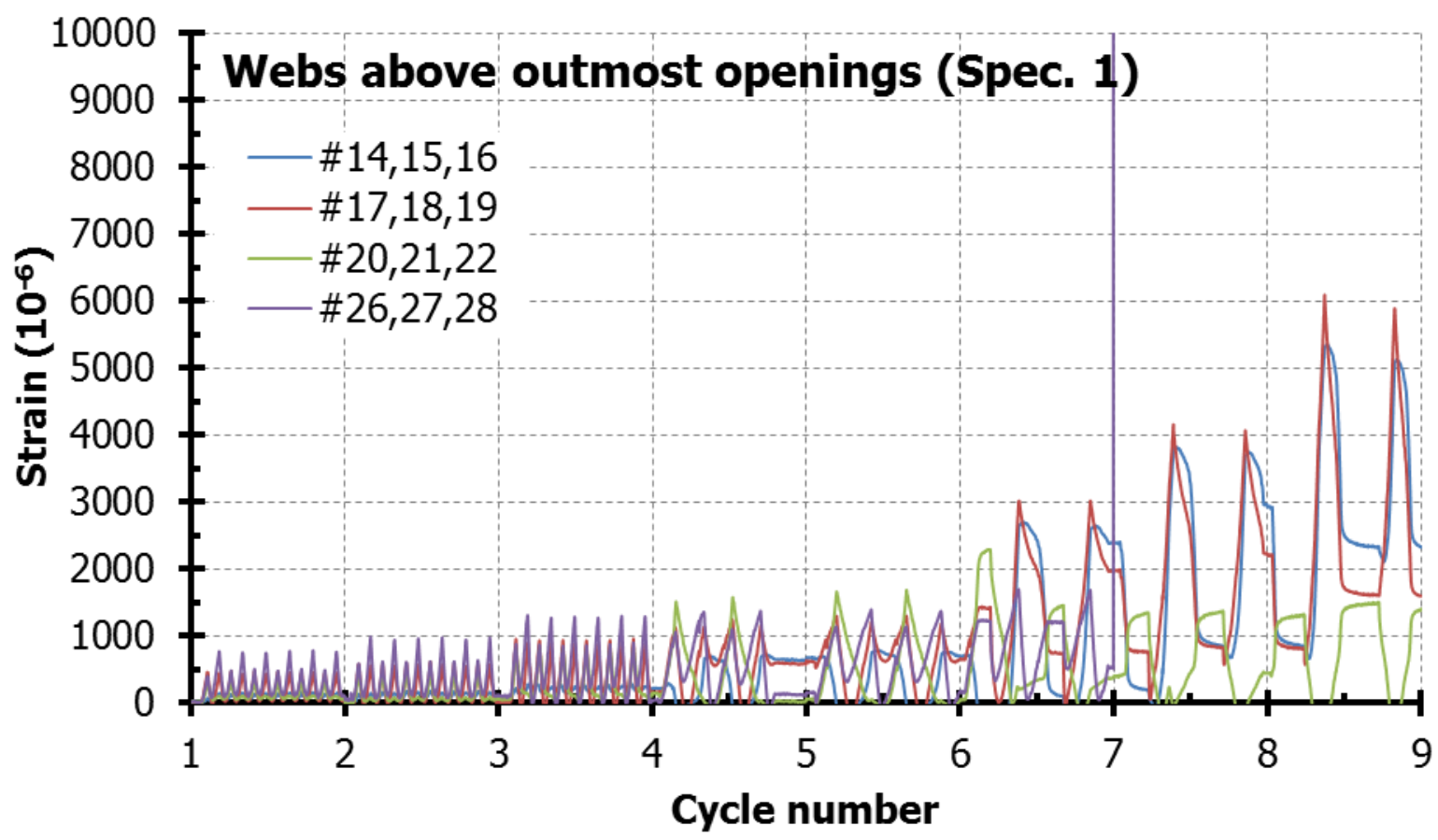




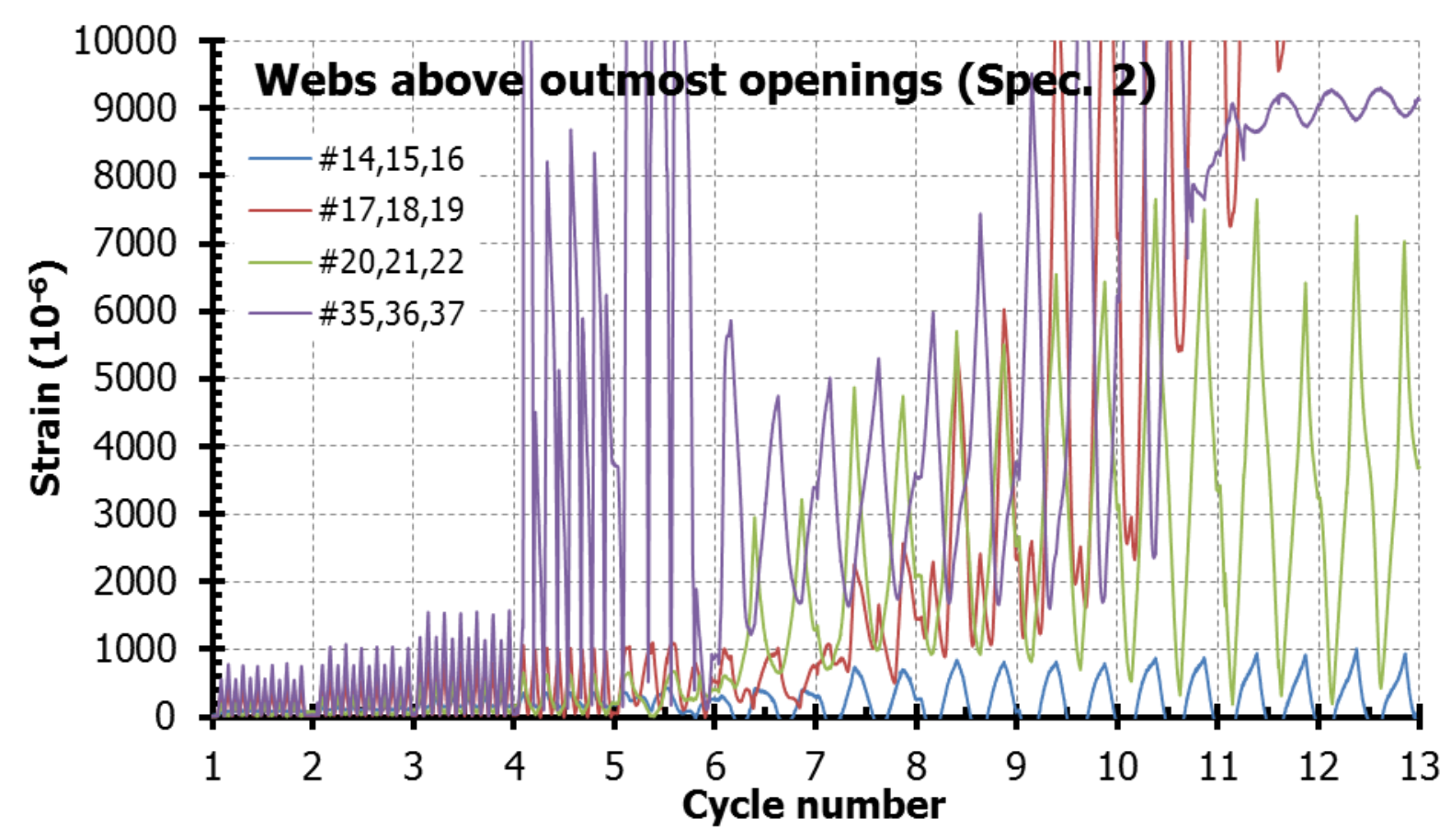

797

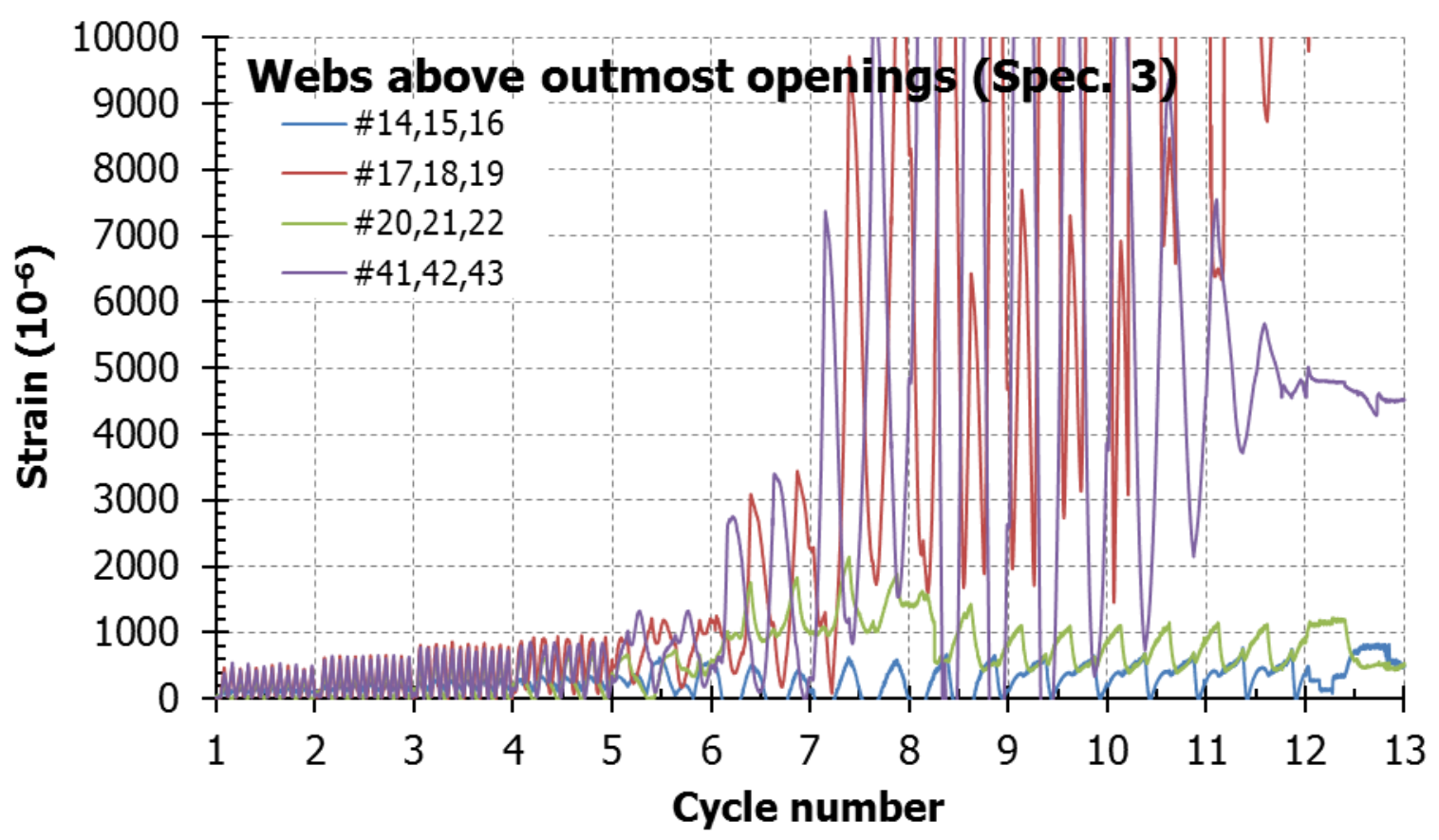

798

799

800 


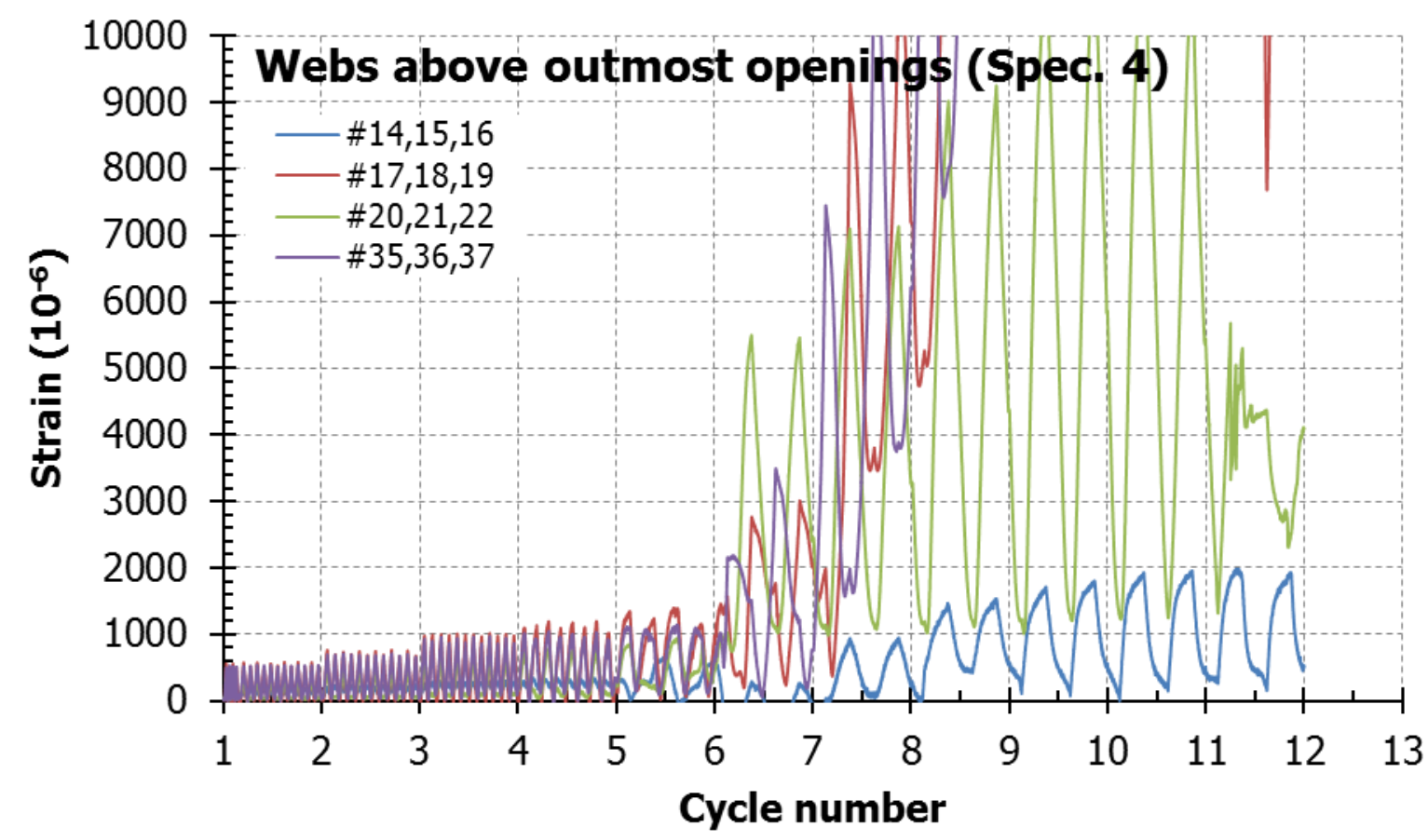

801

802

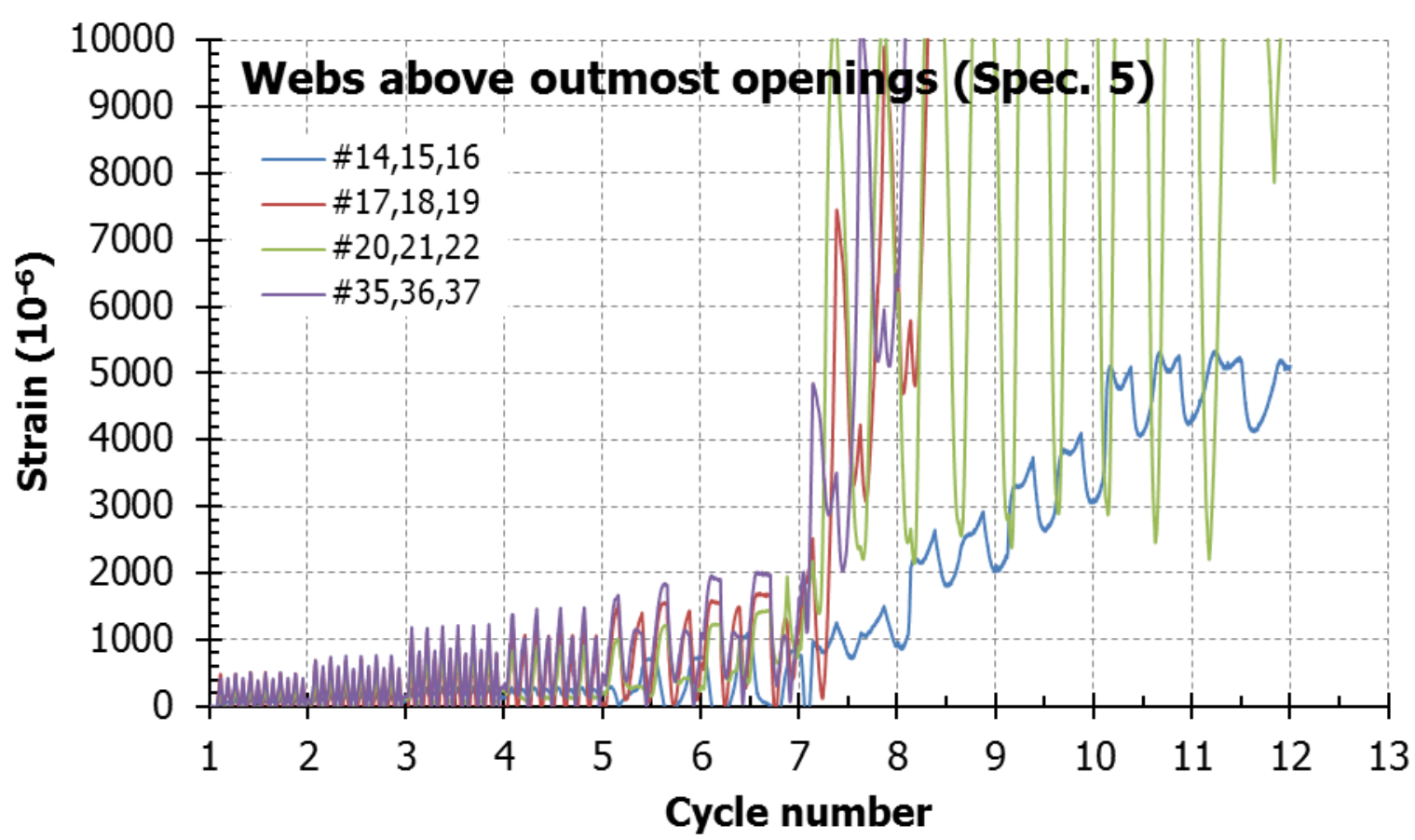

803

804 Figure 17 - Maximum principal strains at the webs above the outmost openings (each cycle 805 number stands for a story drift level, as noted in Figure 9)

806

807 


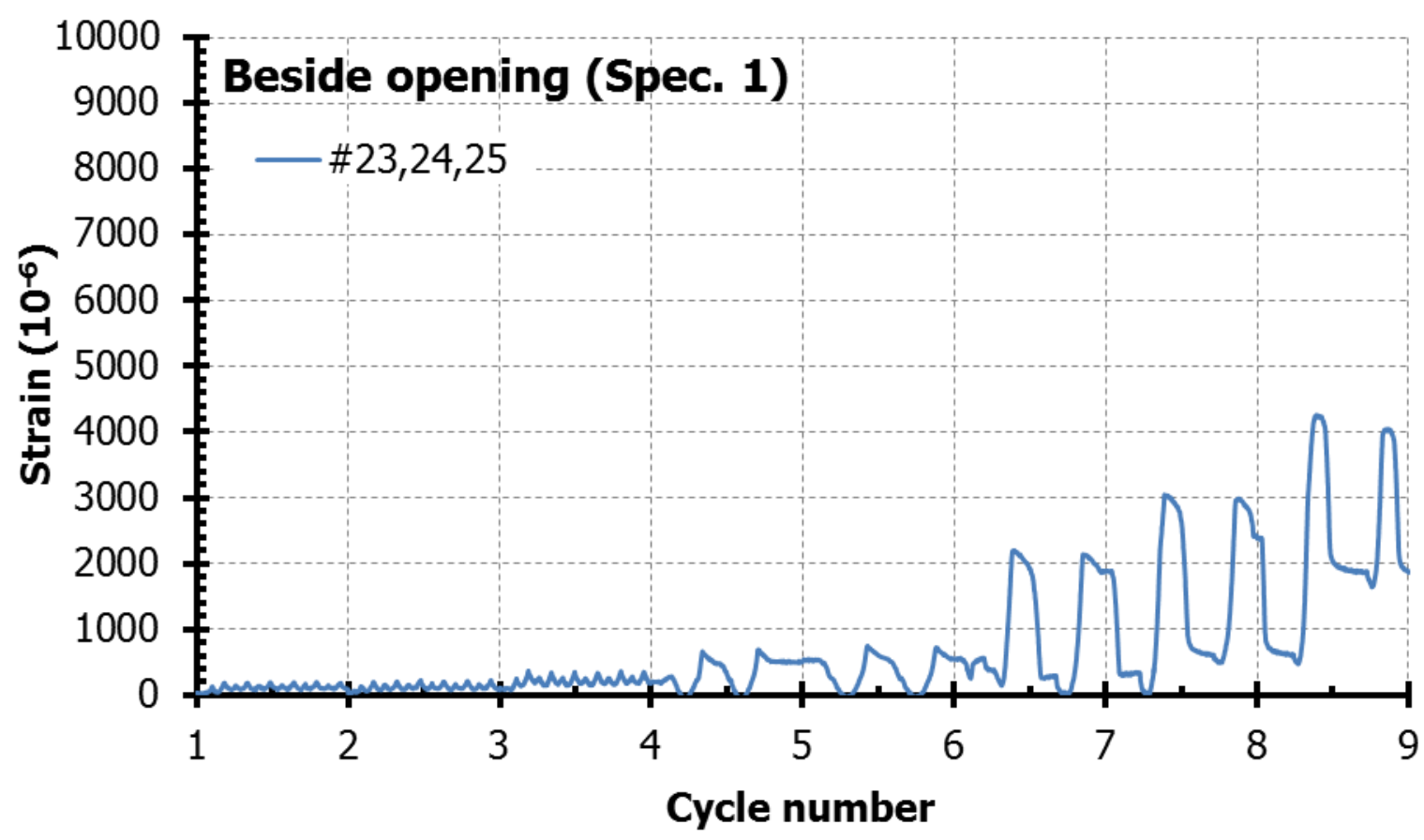

808

809

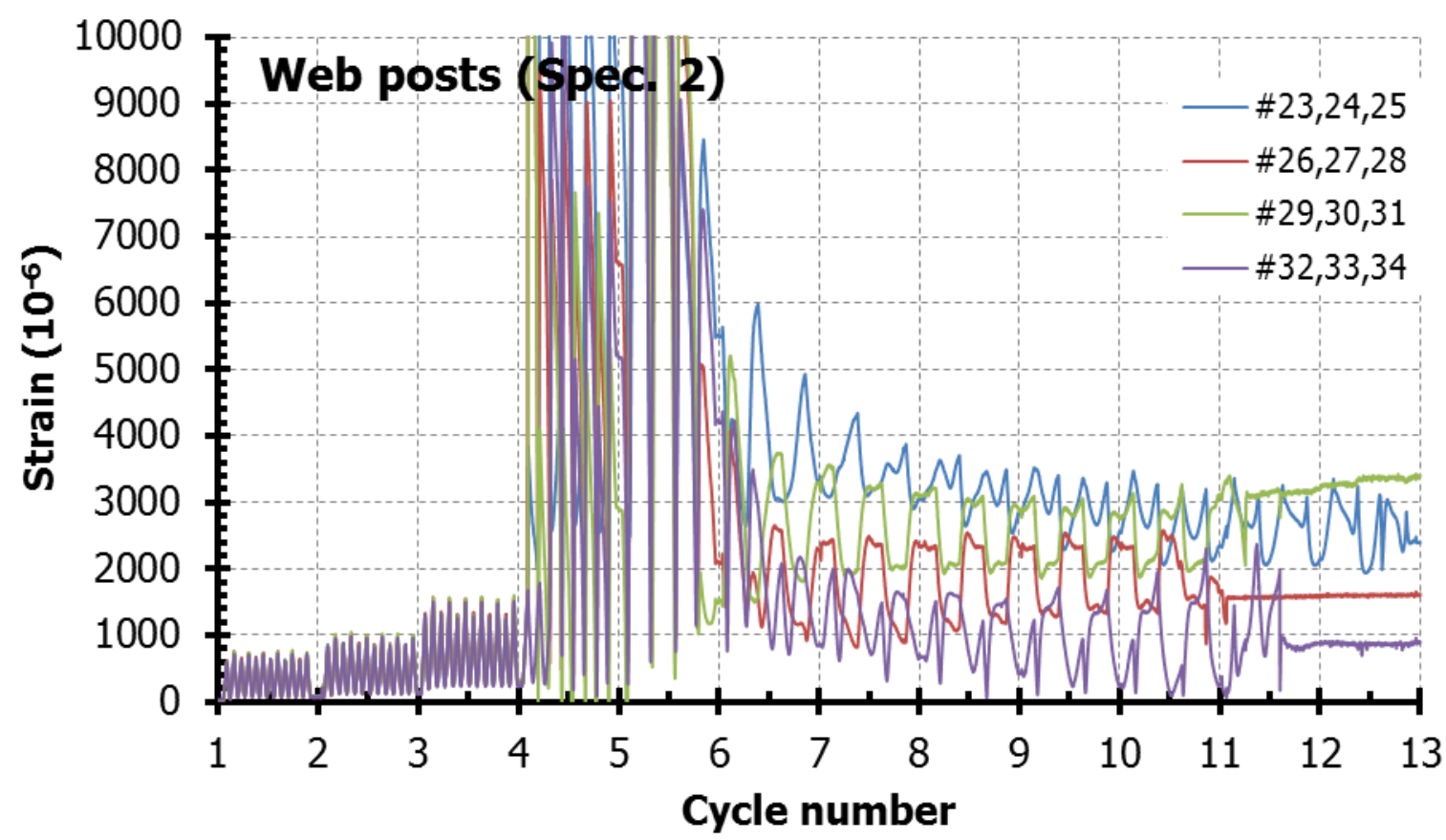

810

811

812 


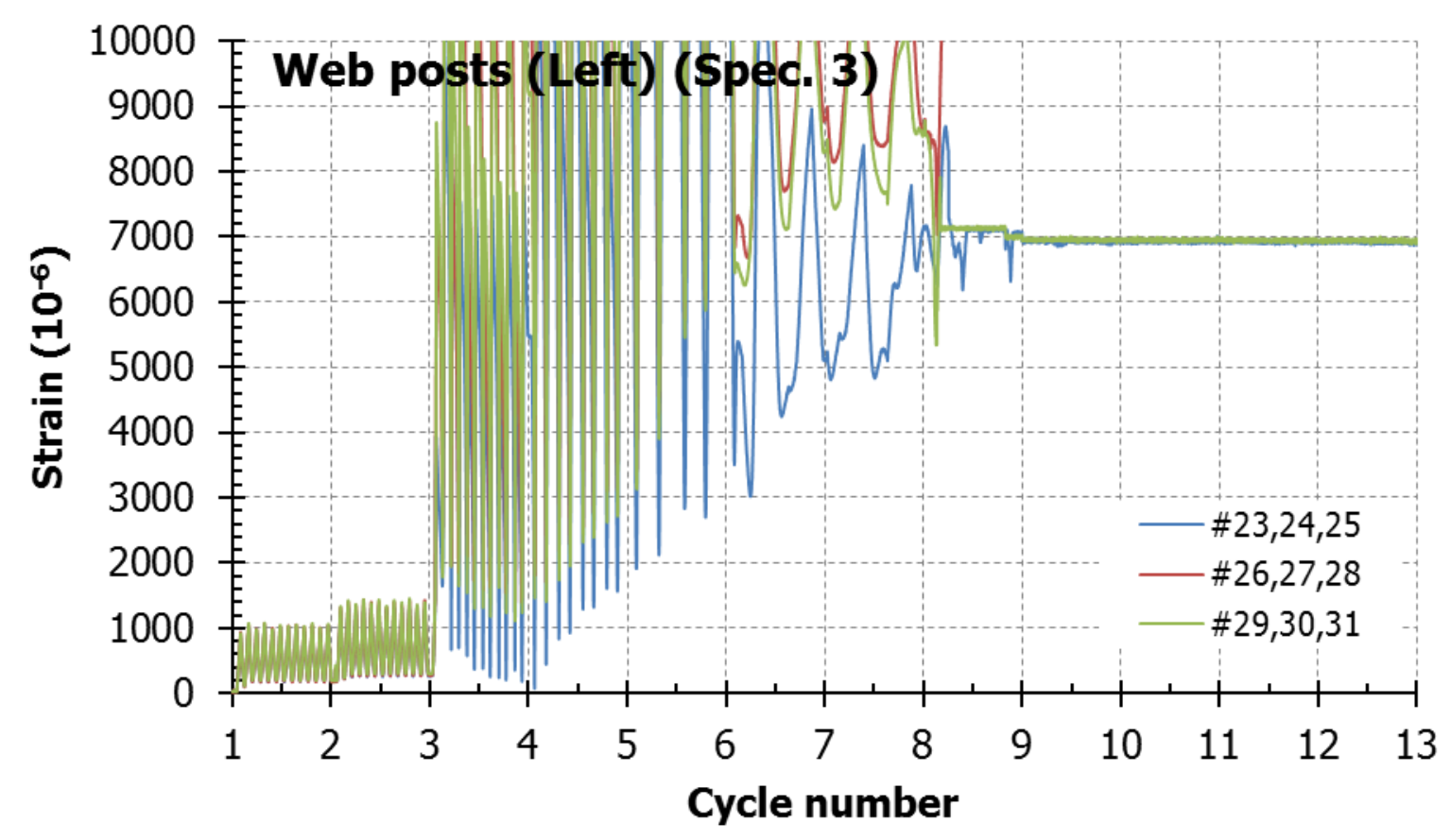

813

814

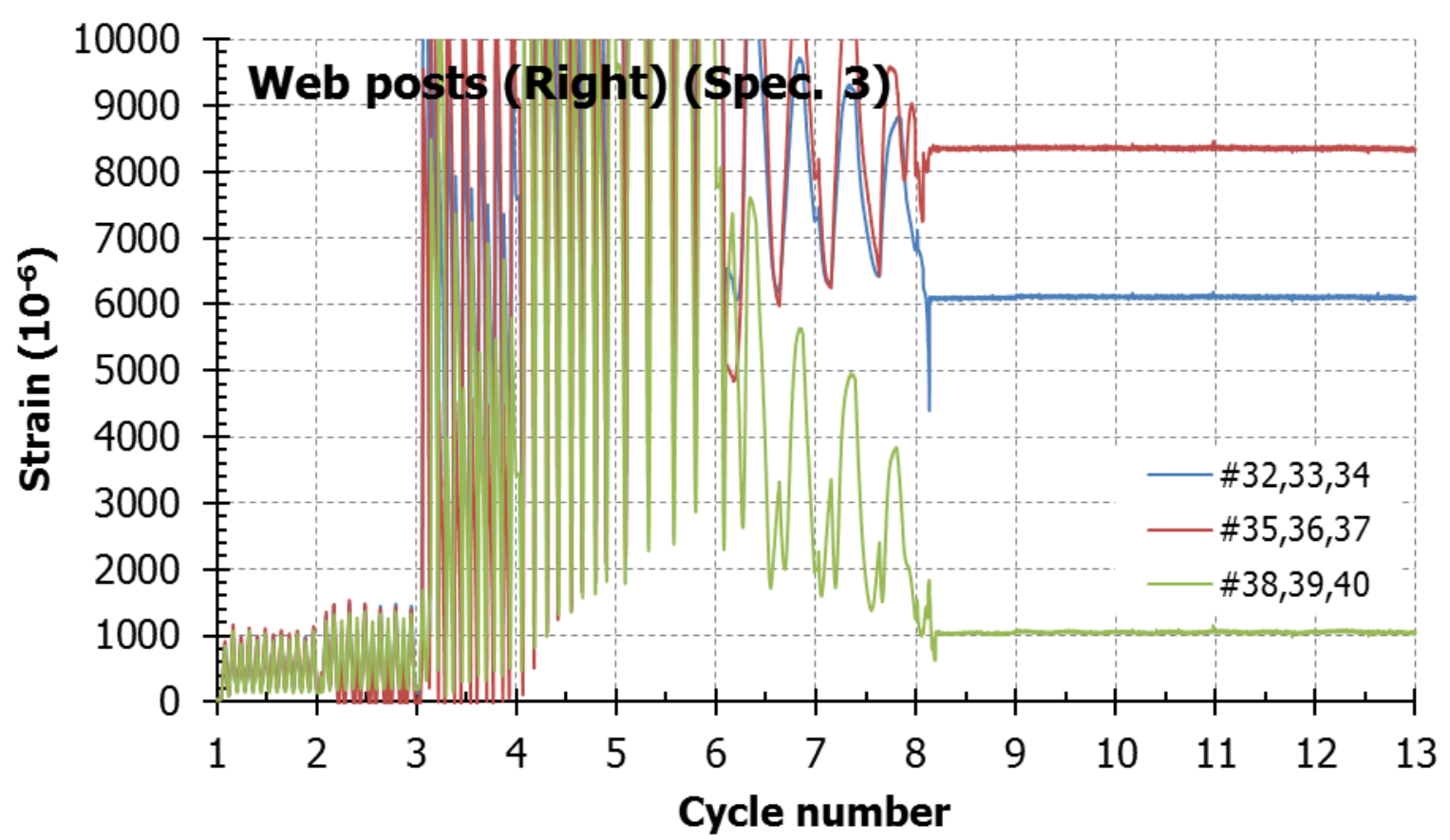

815

816

817 


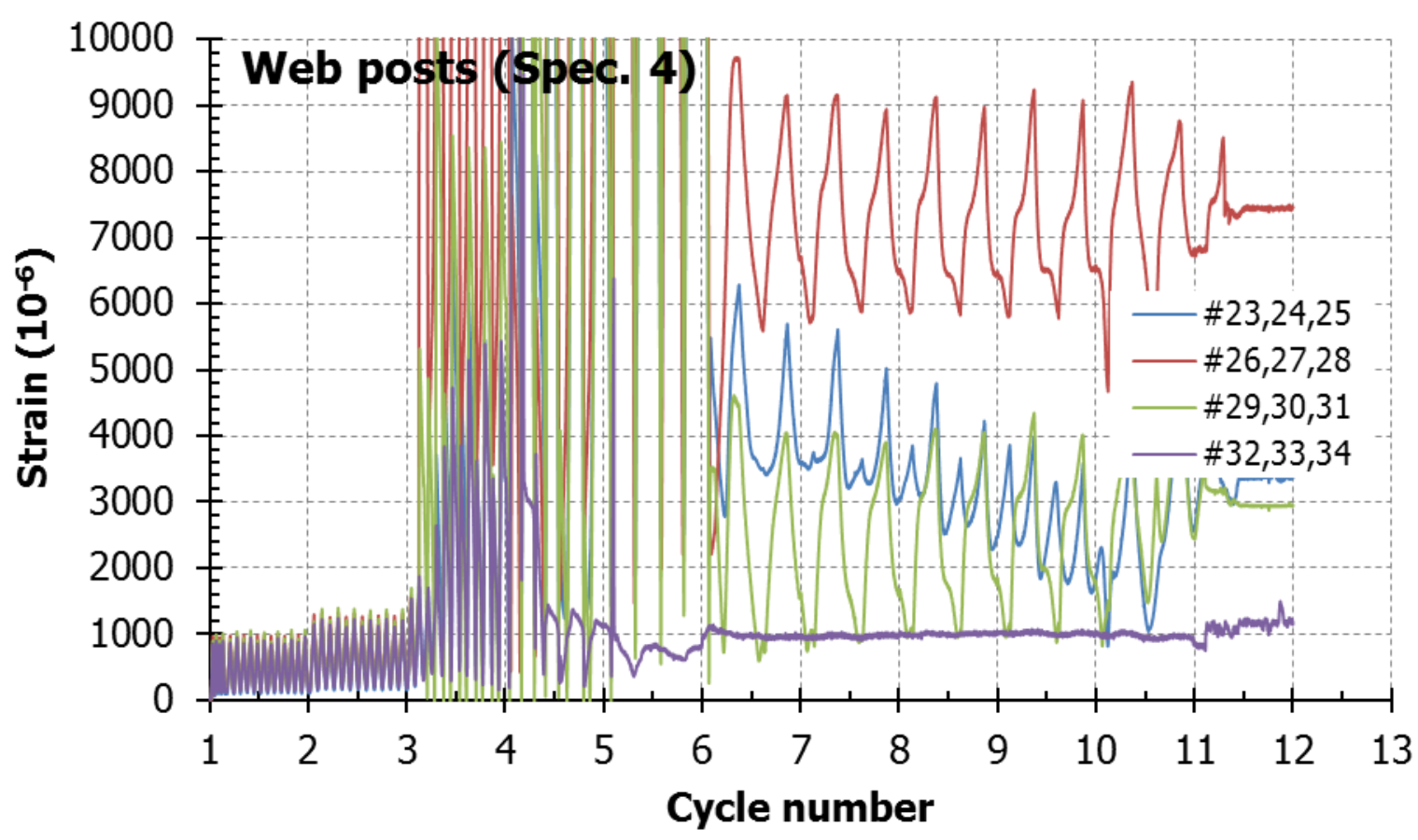

818

Cycle number

819

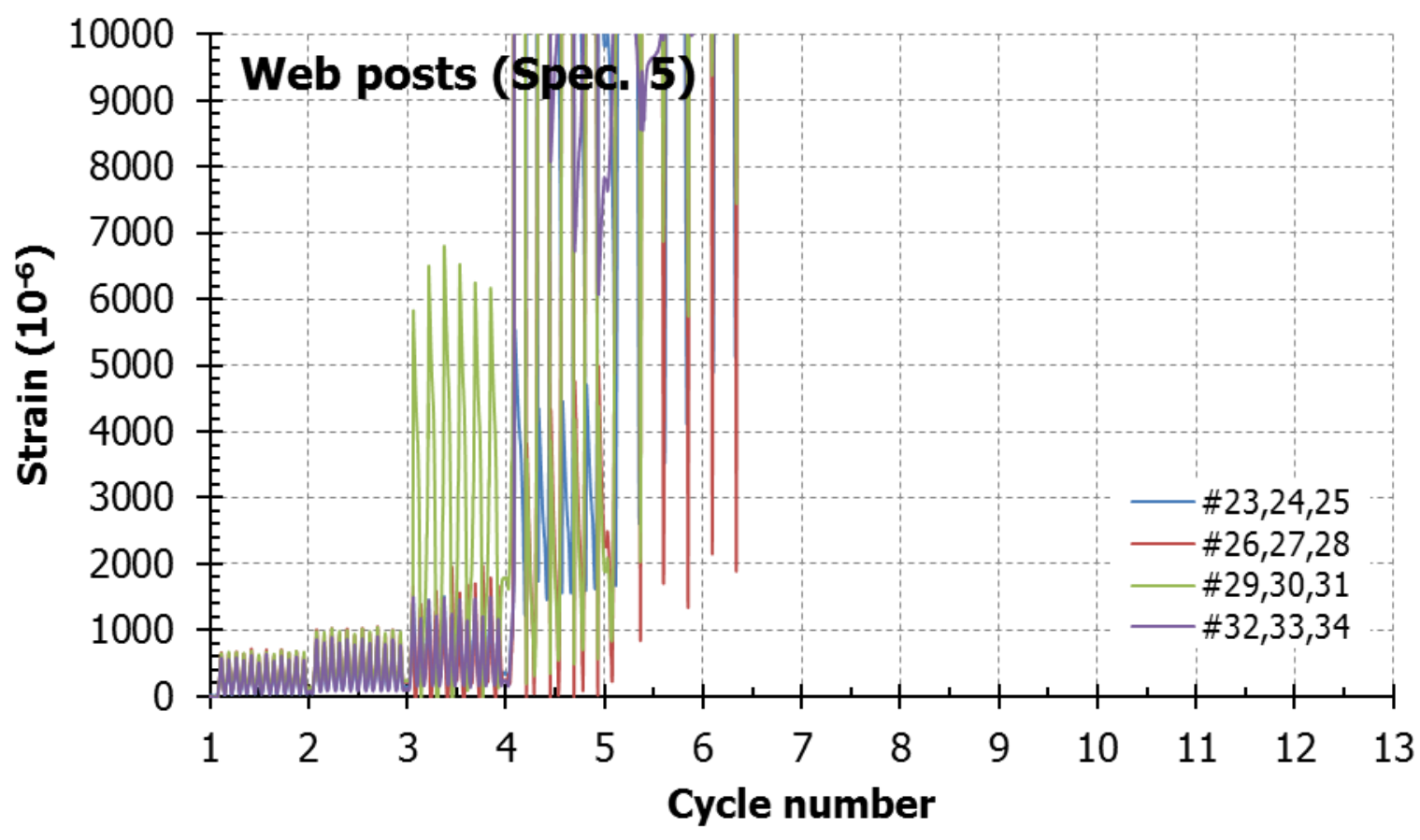

820

821 Figure 18 - Maximum principal strains at the wep posts (each cycle number stands for a story

822 drift level, as noted in Figure 9)

823

824 
825 Table 1 - Design details of Specimens 1 to 5

\begin{tabular}{|c|c|c|c|c|c|c|}
\hline Spec. & $\begin{array}{l}\text { Beam } \\
\text { shape }\end{array}$ & $\begin{array}{c}\text { Number of } \\
\text { web openings }\end{array}$ & $\begin{array}{l}\text { Diameter of } \\
\text { openings } \\
\text { nearest } \\
\text { connections, } \\
\text { in. }(\mathrm{mm})\end{array}$ & $\begin{array}{l}\text { Dimensions } \\
\text { of interior } \\
\text { openings, } \\
\text { in. }(\mathrm{mm})\end{array}$ & $\begin{array}{c}\text { Spacing } \\
\text { between } \\
\text { openings, } \\
\text { in }(\mathrm{mm})\end{array}$ & $\begin{array}{l}\text { Slenderness } \\
\text { ratio of web } \\
\text { posts* }\left(s / d^{\prime}\right)\end{array}$ \\
\hline 1 & W21x68 & 2 & $\begin{array}{c}16.5 \\
(419)\end{array}$ & - & $\begin{array}{c}64.5 \\
(1638)\end{array}$ & - \\
\hline 2 & W21x68 & 5 & $\begin{array}{c}16.0 \\
(406)\end{array}$ & $\begin{array}{l}16.0(406) \\
\text { in dia. }\end{array}$ & $\begin{array}{c}4.25 \\
(108)\end{array}$ & 1.27 \\
\hline 3 & W21x68 & 7 & $\begin{array}{c}16.0 \\
(406)\end{array}$ & $\begin{array}{l}10.0(254) \\
\text { in dia. }\end{array}$ & $\begin{array}{l}2.33 \\
(59)\end{array}$ & 1.23 \\
\hline 4 & W21x68 & 5 & $\begin{array}{l}16.0 \\
(406)\end{array}$ & $\begin{array}{l}16.0(406) \\
\text { in length } \\
8.0(203) \\
\text { in height }\end{array}$ & $\begin{array}{l}4.25 \\
(108)\end{array}$ & 1.52 \\
\hline 5 & W21x68 & 5 & $\begin{array}{l}16.0 \\
(406)\end{array}$ & $\begin{array}{c}16.0(406) \\
\text { in length } \\
4.25(108) \\
\text { in height }\end{array}$ & $\begin{array}{l}4.25 \\
(108)\end{array}$ & 2.00 \\
\hline
\end{tabular}

826 *Slenderness ratio of web posts $=$ distance between the centers of semi-circular openings $/$ 827 height of interior openings

828

829 
830 Table 2 - Tension test results for steel

\begin{tabular}{|c|c|c|c|c|c|}
\hline Specimens & Location & $\begin{array}{c}\text { Upper yield } \\
\text { stress } \\
(\mathrm{ksi})\end{array}$ & $\begin{array}{c}\text { Dynamic yield } \\
\text { stress at } \\
0.002 \text { offset }\end{array}$ & $\begin{array}{c}\text { Strain at the } \\
\text { onset of strain } \\
\text { hardening } \\
(\%)\end{array}$ & $\begin{array}{c}\text { Initial strain } \\
\text { hardening } \\
\text { modulus } \\
(\mathrm{ksi})\end{array}$ \\
\hline \multirow{4}{*}{1,2 , and 3 } & Flange & 56.5 & 52.8 & 2.04 & 342 \\
\cline { 2 - 6 } & Web & 53.8 & 51.4 & 1.49 & 322 \\
\hline \multirow{3}{*}{4 and 5 } & Flange & 58.8 & 57.0 & 3.33 & 243 \\
\cline { 2 - 6 } & \multirow{2}{*}{ Web } & 57.9 & 56.2 & 2.78 & 429 \\
\hline & 56.7 & 54.5 & 1.73 & 523 \\
& & 51.6 & 56.6 & 2.27 & 382 \\
\hline
\end{tabular}

831

\begin{tabular}{|c|c|c|c|c|}
\hline \multirow{2}{*}{ Specimens } & Location & $\begin{array}{c}\text { Modulus of } \\
\text { elasticity } \\
(\mathrm{ksi})\end{array}$ & $\begin{array}{c}\text { Tensile strength } \\
(\mathrm{ksi})\end{array}$ & $\begin{array}{c}\text { Elongation } \\
(\%)\end{array}$ \\
\hline \multirow{3}{*}{1,2 , and 3 } & \multirow{2}{*}{ Flange } & 32,900 & 69.4 & 25 \\
& \multirow{2}{*}{ Web } & 31,500 & 68.3 & 28 \\
\cline { 2 - 5 } & \multirow{2}{*}{ Flange } & 32,500 & 69.5 & 26 \\
& \multirow{2}{*}{ Web 5} & 32,500 & 69.8 & 26 \\
\cline { 2 - 5 } & \multirow{2}{*}{ Web 5} & 32,700 & 70.2 & 23 \\
& & 32,700 & 71.5 & 26 \\
\hline
\end{tabular}

832

Note: $1 \mathrm{ksi}=6.895 \mathrm{MPa}$
833

834

835

836

837

838

Table 3 - Manufacturer's mill test data for steel

\begin{tabular}{|c|c|c|c|}
\hline Specimens & $\begin{array}{c}\text { Yield strength } \\
(\mathrm{ksi})\end{array}$ & $\begin{array}{c}\text { Tensile strength } \\
(\mathrm{ksi})\end{array}$ & $\begin{array}{c}\text { Elongation } \\
(\%)\end{array}$ \\
\hline \multirow{2}{*}{ 1, 2, and 3 } & 59 & 77 & 22 \\
& 61 & 77 & 24 \\
\hline \multirow{2}{*}{ 4 and 5 } & 57 & 75 & 21 \\
& 58 & 77 & 26 \\
\hline
\end{tabular}

Note: $1 \mathrm{ksi}=6.895 \mathrm{MPa}$ 
839 Table 4 - Plastic analysis based on Von-Mises and Tresca Criterions [Eqs. (1) through (7)]

\begin{tabular}{|c|c|c|c|c|c|c|c|c|}
\hline $\begin{array}{l}\text { Based on Von- } \\
\text { Mises criterion }\end{array}$ & \multicolumn{2}{|c|}{ Specimen 2} & \multicolumn{2}{|c|}{ Specimen 3} & \multicolumn{2}{|c|}{ Specimen 4} & \multicolumn{2}{|c|}{ Specimen 5} \\
\hline$V_{w p, s}$ (kips) & \multicolumn{2}{|c|}{62.0} & \multicolumn{2}{|c|}{34.0} & \multicolumn{2}{|c|}{61.2} & \multicolumn{2}{|c|}{61.2} \\
\hline$V_{w p, f}($ kips $)$ & \multicolumn{2}{|c|}{61.6} & \multicolumn{2}{|c|}{31.6} & \multicolumn{2}{|c|}{87.8} & \multicolumn{2}{|c|}{125.0} \\
\hline $\begin{array}{l}\text { Plastified T- } \\
\text { sections }^{2)}\end{array}$ & $\begin{array}{c}\text { w/ } \\
\text { Comp. }\end{array}$ & $\begin{array}{c}\text { w/ } \\
\text { Tens. }\end{array}$ & $\begin{array}{c}\mathrm{w} / \\
\text { Comp. }\end{array}$ & $\begin{array}{c}\text { w/ } \\
\text { Tens. }\end{array}$ & $\begin{array}{c}\text { w/ } \\
\text { Comp. }\end{array}$ & $\begin{array}{c}\text { w/ } \\
\text { Tens. }\end{array}$ & $\begin{array}{c}\text { w/ } \\
\text { Comp. }\end{array}$ & $\begin{array}{c}\text { w/ } \\
\text { Tens. }\end{array}$ \\
\hline$C(\text { kips })^{3)}$ & 123 & -123 & 94.7 & -94.7 & 122 & -122 & 122 & -122 \\
\hline$y_{P N A}$ (in.) & 0.518 & 0.264 & 0.489 & 0.294 & 0.519 & 0.264 & 0.519 & 0.264 \\
\hline$M_{T}$ (kip-in.) & 123 & 95.3 & 123 & 102 & 121 & 93.8 & 121 & 93.8 \\
\hline$L^{\prime}(\mathrm{ft})$ & \multicolumn{2}{|c|}{81} & \multicolumn{2}{|c|}{81} & \multicolumn{2}{|c|}{81} & \multicolumn{2}{|c|}{81} \\
\hline$d$ (in.) & \multicolumn{2}{|c|}{20.1} & \multicolumn{2}{|c|}{20.1} & \multicolumn{2}{|c|}{20.1} & \multicolumn{2}{|c|}{20.1} \\
\hline$V_{v}^{4)}$ (kips) & \multicolumn{2}{|c|}{66.6} & \multicolumn{2}{|c|}{53.1} & \multicolumn{2}{|c|}{66.8} & \multicolumn{2}{|c|}{66.8} \\
\hline$V_{\text {Mises }}^{5)}(\mathrm{kips})$ & \multicolumn{2}{|c|}{95.3} & \multicolumn{2}{|c|}{76.0} & \multicolumn{2}{|c|}{95.5} & \multicolumn{2}{|c|}{95.5} \\
\hline
\end{tabular}

840

\begin{tabular}{|c|c|c|c|c|c|c|c|c|}
\hline $\begin{array}{l}\text { Based on Tresca } \\
\text { yield criterion }\end{array}$ & \multicolumn{2}{|c|}{ Specimen 2} & \multicolumn{2}{|c|}{ Specimen 3} & \multicolumn{2}{|c|}{ Specimen 4} & \multicolumn{2}{|c|}{ Specimen 5} \\
\hline$V_{w p, s}{ }^{1)}(\mathrm{kips})$ & \multicolumn{2}{|c|}{53.7} & \multicolumn{2}{|c|}{29.5} & \multicolumn{2}{|c|}{53.0} & \multicolumn{2}{|c|}{53.0} \\
\hline$V_{w p, f}($ kips $)$ & \multicolumn{2}{|c|}{61.6} & \multicolumn{2}{|c|}{31.6} & \multicolumn{2}{|c|}{87.8} & \multicolumn{2}{|c|}{125.0} \\
\hline $\begin{array}{c}\text { Plastified T- } \\
\text { sections }\end{array}$ & $\begin{array}{c}\text { w/ } \\
\text { Comp. }\end{array}$ & $\begin{array}{c}\text { w/ } \\
\text { Tens. }\end{array}$ & $\begin{array}{c}\text { w/ } \\
\text { Comp. }\end{array}$ & $\begin{array}{c}\mathrm{w} / \\
\text { Tens. }\end{array}$ & $\begin{array}{c}\text { w/ } \\
\text { Comp. }\end{array}$ & $\begin{array}{l}\text { w/ } \\
\text { Tens. }\end{array}$ & $\begin{array}{c}\text { w/ } \\
\text { Comp. }\end{array}$ & $\begin{array}{l}\text { w/ } \\
\text { Tens. }\end{array}$ \\
\hline$C(\text { kips })^{3)}$ & 107 & -107 & 88.4 & -88.4 & 106 & -106 & 106 & -106 \\
\hline$y_{P N A}$ (in.) & 0.502 & 0.281 & 0.482 & 0.301 & 0.502 & 0.281 & 0.502 & 0.281 \\
\hline$M_{T}$ (kip-in.) & 123 & 98.9 & 123 & 103 & 121 & 97.6 & 121 & 97.6 \\
\hline$L^{\prime}(\mathrm{ft})$ & \multicolumn{2}{|c|}{81} & \multicolumn{2}{|c|}{81} & \multicolumn{2}{|c|}{81} & \multicolumn{2}{|c|}{81} \\
\hline$d$ (in.) & \multicolumn{2}{|c|}{20.1} & \multicolumn{2}{|c|}{20.1} & \multicolumn{2}{|c|}{20.1} & \multicolumn{2}{|c|}{20.1} \\
\hline$V_{v}^{4)}(\mathrm{kips})$ & \multicolumn{2}{|c|}{58.9} & \multicolumn{2}{|c|}{50.0} & \multicolumn{2}{|c|}{58.7} & \multicolumn{2}{|c|}{58.7} \\
\hline$V_{\text {Tresca }}{ }^{5)}$ (kips) & \multicolumn{2}{|c|}{84.2} & \multicolumn{2}{|c|}{71.5} & \multicolumn{2}{|c|}{83.9} & \multicolumn{2}{|c|}{83.9} \\
\hline
\end{tabular}

841 1) Determined by Eq. (1) using $f_{y} / 2$ instead of $f_{y} / \sqrt{3}$

842 2) T-sections above and below the center of the opening closest to the connection (see Figure 5)

843 3) Axial force equal to one-half of the smallest of $V_{w p, s}$ and $V_{w p, f}$ times the number of web posts

844 4) Beam shear determined by Eq. (7)

845 5) Story shear associated with beam shear 
Table 5 - Comparison of test and plastic analysis results

\begin{tabular}{|c|c|c|c|c|c|c|c|c|c|c|c|c|}
\hline \multirow{3}{*}{ Spec. } & \multicolumn{8}{|c|}{ Test results } & \multicolumn{4}{|c|}{$\begin{array}{l}\text { Story shear from plastic } \\
\text { analysis }\end{array}$} \\
\hline & \multicolumn{2}{|c|}{$\begin{array}{l}\text { Maximum } \\
\text { story shear } \\
V_{\max } \text { (kips) } \\
\end{array}$} & \multicolumn{2}{|c|}{$\begin{array}{c}\text { Story drift at } \\
V_{\max }(\%)\end{array}$} & \multicolumn{2}{|c|}{$\begin{array}{l}\text { Story shear at } \\
\text { yield point } \\
\text { (kips) }\end{array}$} & \multicolumn{2}{|c|}{$\begin{array}{l}\text { Story drift at } \\
\text { yield point }{ }^{1)} \\
(\%)\end{array}$} & \multicolumn{2}{|c|}{$\begin{array}{l}\text { Based on Von- } \\
\text { Mises yield } \\
\text { criterion }\end{array}$} & \multicolumn{2}{|c|}{$\begin{array}{c}\text { Based on } \\
\text { Tresca yield } \\
\text { criterion }\end{array}$} \\
\hline & $(+)$ & $(-)$ & $(+)$ & $(-)$ & $(+)$ & $(-)$ & $(+)$ & $(-)$ & $\begin{array}{l}V_{\text {Mises }} \\
\text { (kips) }\end{array}$ & $\begin{array}{l}V_{\text {Mises }} / \\
V_{\max } / \\
\end{array}$ & $\begin{array}{l}V_{\text {Tresca }} \\
\text { (kips) }\end{array}$ & \begin{tabular}{|l}
$V_{\text {Trescal }} /$ \\
$V_{\max }$ \\
\end{tabular} \\
\hline $1^{4)}$ & +130 & -130 & - & - & - & - & - & - & - & - & - & - \\
\hline 2 & +77.8 & -80.0 & +1.49 & -1.48 & +72.5 & -62.8 & +1.01 & -0.80 & 95.3 & 1.22 & 84.2 & 1.08 \\
\hline 3 & +70.3 & -72.0 & +1.47 & -1.49 & +58.2 & -53.7 & +0.74 & -0.67 & 76.0 & 1.08 & 71.5 & 1.01 \\
\hline 4 & +90.6 & -90.6 & +1.49 & -1.48 & +69.8 & -72.2 & +0.77 & -0.78 & 95.5 & 1.05 & 83.9 & 0.92 \\
\hline 5 & +96.0 & -102 & +1.43 & -1.97 & +72.1 & -76.6 & +0.81 & -1.01 & 95.5 & 0.99 & 83.9 & 0.87 \\
\hline
\end{tabular}

848

849

850

851

852

853

854

855

856

857

858

859

Note: $1 \mathrm{kip}=4.45 \mathrm{kN}$

1) The yield point in the experimental load-drift curve is determined based on ATC 24 [23], at the intersection point between the secant of the load-drift curve from the origin to the point of $75 \%$ the maximum load and the horizontal line passing through the maximum load.

2) The plastic analyses assume that Mode-B mechanisms develop in Specimens 2 to 5. The plastic analysis for Specimen 1, associated with a Mode-A mechanism, is explained in a companion paper [19].

3) $V_{\max }$ in the positive direction is used for this ratio.

4) The test of Specimen 1 was not completed due to hardware limitations.

Table 6 - Story drift at the yielding of each portion of the specimen

\begin{tabular}{|c|c|c|c|c|c|c|}
\hline Portion & Gages & Specimen 1 & Specimen 2 & Specimen 3 & Specimen 4 & Specimen 5 \\
\hline $\begin{array}{c}\text { Flanges at } \\
\text { connections }\end{array}$ & $\begin{array}{c}\# 1,2,3,7, \\
8,9\end{array}$ & n.y. & n.y. & n.y. & n.y. & n.y. \\
\hline $\begin{array}{c}\text { Flange } \\
\text { above } \\
\text { leftmost } \\
\text { opening }\end{array}$ & $\# 4,5,6$ & n.y. & $3 \sim 4 \%$ & $3 \%$ & $3 \%$ & $3 \%$ \\
\hline $\begin{array}{c}\text { Webs } \\
\text { above } \\
\text { outmost } \\
\text { openings }\end{array}$ & $\begin{array}{c}\#[14,15,16], \\
\#[17,18,19], \\
\text { etc. }\end{array}$ & $2 \%$ & $1 \sim 1.5 \%$ & $2 \%$ & $2 \%$ & $3 \%$ \\
\hline $\begin{array}{c}\text { Web } \\
\text { around } \\
\text { leftmost } \\
\text { opening }\end{array}$ & $\begin{array}{c}\# 10,11,12, \\
13\end{array}$ & $1 \%$ & $1.5 \%$ & $1.5 \%$ & $1.5 \%$ & $1 \sim 1.5 \%$ \\
\hline Web posts & $\begin{array}{c}\#[23,24,25], \\
\text { etc. }\end{array}$ & $2 \sim 3 \%$ & $1 \%$ & $0.75 \%$ & $0.75 \%$ & $0.75 \%$ \\
\hline
\end{tabular}

Note: "n.y." indicates no yielding. 